\title{
Monetary policy and market interest rates*
}

\author{
Tore Ellingsen $\quad$ Ulf Söderström ${ }^{\dagger}$ \\ Working Paper in Economics and Finance No. 242 \\ Stockholm School of Economics \\ Original version: May, 1998 \\ Revised version: March, 1999
}

\begin{abstract}
We investigate, theoretically and empirically, the relationship between monetary policy and the term structure of interest rates. In particular, we show in a dynamic macroeconomic model that if monetary policy reveals information about economic developments, interest rates of all maturities move in the same direction in response to a policy innovation. If, on the other hand, monetary policy reveals information about the central bank's policy preferences, short and long interest rates move in opposite directions. In the empirical section, we provide direct measures of endogenous and exogenous monetary policy innovations in the U.S. by analyzing the reaction of financial market participants to Federal Reserve policy moves. The empirical findings support the theoretical predictions.
\end{abstract}

Keywords: Monetary policy, term structure of interest rates, event studies, central bank private information.

JEL Classification: E43, E52.

${ }^{*}$ We are grateful for helpful comments from Annika Alexius, Pierluigi Balduzzi, Hans Dillén, Øyvind Eitrheim, Torsten Persson, Weshah Razzak, Asbjørn Rødseth, Glenn Rudebusch, Patrik Säfvenblad, Peter Sellin, Paul Söderlind, Lars Svensson, Jouko Vilmunen, and Anders Vredin; seminar participants at the Stockholm School of Economics, the Institute for International Economic Studies, the Norwegian School of Economics and Business, Norges Bank, and Sveriges Riksbank; and to Gisela Waisman for research assistance. We also acknowledge financial support from the Tore Browaldh Foundation and Sveriges Riksbank. The views expressed in this paper are those of the authors, and do not necessarily reflect those of Sveriges Riksbank.

${ }^{\dagger}$ Address: Department of Economics, Stockholm School of Economics, Box 6501, SE-113 83 Stockholm, Sweden. E-mail: tore.ellingsen@hhs.se, ulf.soderstrom@hhs.se. 


\section{Introduction}

Understanding the relationship between monetary policy and market interest rates is of utmost importance to bond traders and central bankers alike. Unanticipated changes in monetary policy strongly affect interest rates of almost all maturities, representing recurrent opportunities for traders to win or lose money. All serious bond analysts have their own quantitative model of the past relationship between policy moves and the yield curve. Policymakers on the other hand carefully watch the yield curve for news about market expectations. Academic economists are interested too: the effect of monetary policy on the real economy is one of our discipline's more controversial topics.

Given these efforts, our understanding of yield curve movements remains remarkably incomplete. True, there are some statistical regularities. It is empirically well established that monetary policy affects market interest rates, and that on average this relationship is positive; an increase in the central bank rate leads to an increase in interest rates of all maturities. It is also well known, however, that there are many exceptions to the rule. ${ }^{1}$ For example, on a number of occasions in 1994 when the Federal Reserve announced an increase in its target rate, interest rates of long maturities fell. As noted by Skinner and Zettelmeyer (1995), who study the interest rate response to monetary policy over long periods in four major economies, the fraction of such 'abnormal' responses is considerable in all countries.

At the moment, there is no coherent theory which tells us whether the yield curve will shift or rotate after a policy change. Some argue that the curve should always shift. For example, Cook and Hahn (1989), who first firmly established the positive empirical relationship between target rates and long rates, interpret their finding as supportive of the expectations theory of the term structure. ${ }^{2}$ The expectations theory says that a long interest rate should be equal to the sum of short interest rates over the same period of time plus a term premium; thus an increase in the first couple of short rates should drive up the long rate too, but by less. Romer and Romer (1996) disagree. To them, the positive movement in the long rate is inconsistent with standard monetary theory - a puzzle. According to received theory, they claim, an increase in short rates should reduce inflation, and

\footnotetext{
${ }^{1}$ The classic study which documents the positive relationship for the United States is by Cook and Hahn (1989). We refer to similar studies for other countries below. The fact that there are many exceptions to the rule has been discussed extensively by central bankers; see, e.g., Roley and Sellon (1995).

${ }^{2}$ This view is echoed by, e.g., Mehra (1996) and Skinner and Zettelmeyer (1995).
} 
hence reduce the level of sufficiently long rates. Romer and Romer suggest that the puzzle can be resolved if the central bank has access to private information about economic fundamentals, but they do not develop their argument formally.

In this paper, we provide a model within which each of the three mechanisms captured by the 'standard' theory, the expectations hypothesis, and Romer and Romer (1996), respectively, are all at play. This model is rich enough to allow a wide variety of market reactions to monetary policy, yet structured enough to allow a simple empirical evaluation. Our argument centers around the presumption that a change in monetary policy can come about for two distinct reasons: either the monetary authorities respond to new and possibly private knowledge about the economy, or their policy preferences change. In the first case, policy is essentially endogenous, reflecting new input into a given objective function; in the second case, policy is exogenous, in the sense that the input is the same but the objective function is new. After an endogenous policy action, our model predicts that interest rates of all maturities move in the same direction as the policy innovation. After an exogenous policy action, on the other hand, short and long interest rates should move in opposite directions. To test this model empirically, it is necessary to classify policy events according to whether they are exogenous or endogenous. We do this by interpreting newspaper reports immediately before and after each event.

Let us now describe our approach in a little more detail. Our theoretical model is taken from Svensson (1997a,b), and is quite simple, with reduced-form relationships for output and inflation. Key features of the economy are that shocks to output and inflation are persistent, and that monetary policy affects output and inflation with a lag. To this model we add an equation describing the term structure of interest rates. The central bank is assumed to control the one-period interest rate and to minimize a loss function which is quadratic in deviations of output and inflation from target. The simplified treatment of the economy allows us to derive the central bank's reaction function endogenously and to obtain a closed-form expression for the yield curve.

Assuming that the expectations hypothesis of the term structure holds, the model yields the following set of predictions. Suppose the central bank's objective function is known and stable. Whenever an economic shock is symmetrically observed by all agents, market interest rates respond immediately, and the change in the central bank rate is fully anticipated. In this case, all interest rates move in the same direction (Proposition 1). Unanticipated changes in the central bank rate can occur for two separate reasons. First, the central bank may have private (i.e., advance) 
information about exogenous shocks to output and prices. In this case, an increase in the short interest rate could be interpreted by market participants as an indication of increased inflation, and as the central bank acts to squeeze inflation out of the economy, interest rates of all maturities go up (Proposition 3). ${ }^{3}$ The existence of central bank private information in the United States has been documented by Romer and Romer (1996), and it is also supported by our event studies. Second, the central bank's preferences may change. The policy preferences of the central bank are captured by the parameter $\lambda_{t}$, which indicates the current weight on output stabilization relative to price stabilization in the bank's objective function. Thus, if the short interest rate is increased, and bond traders are confident that there has been no unanticipated change in the fundamentals, then they will typically infer that price stabilization has moved higher on the central bank's agenda. In this case, we show that sufficiently long interest rates will move in the opposite direction, because average inflation is reduced (Proposition 4). We also note that $\lambda_{t}$ determines the magnitude of the interest rate response to fundamental shocks. For a given shock, short rates respond less and long rates more as we increase $\lambda_{t}$ (Proposition 2).

In this paper, we concentrate on testing Propositions 3 and 4 . To do so, we examine monetary policy in the United States from October 1988 until May 1997. During this sample period, the Federal Reserve has targeted the federal funds rate very strictly, so that changes in the target are much easier to observe than in preceding periods. Most target changes in this period are observed immediately by market participants. Using the commentaries in the Wall Street Journal, we are thus able to extract the reactions of market participants in a fairly consistent way.

The empirical results are encouraging. Policy innovations, measured as the change in the three-month rate on the day the funds rate target is adjusted, have different impact on interest rates depending on the bond market's interpretation of the move. Endogenous policy, driven by economic developments, moves long rates in the same direction as the policy innovation. Truly exogenous policy, driven by central bank preference shifts, moves ten- and thirty-year rates in the opposite direction to the policy innovation.

The paper is organized as follows. We proceed in Section 2 by presenting our theoretical model, and Section 3 develops the main theoretical predictions. In Section 4 , we present the methodology behind, and the results from, our classification

\footnotetext{
${ }^{3}$ However, it is not necessarily true that all future short rates go up. Because the initial increase in the short rate creates a reduction in output, it may have to be offset by future interest rate reductions.
} 
of Federal Reserve policy actions, which we use to study the response of U.S. interest rates to monetary policy shocks. Finally, the importance of the theoretical and empirical results and some possible extensions are discussed in Section 5.

\section{The model}

The model we use is taken from Svensson $(1997 \mathrm{a}, \mathrm{b})$, and is a dynamic version of a simple aggregate supply-aggregate demand model, where we add an equation for the term structure of interest rates. Monetary policy does not affect the inflation rate directly, but only through the level of aggregate demand. An important feature is the introduction of 'control lags' in the response of the economy to monetary policy: policy affects aggregate demand after a lag of one period, and aggregate demand in turn affects the inflation rate in the subsequent period. This feature is consistent with the stylized facts about the response of output and inflation to monetary policy (see, e.g., Bernanke and Gertler, 1995).

\subsection{Setup}

Let $\pi_{t}$ and $y_{t}$ be the percentage deviations at time $t$ of inflation and real output from their 'natural' levels. The inflation process (the aggregate supply relationship) is governed by an accelerationist Phillips curve relation: the change in the inflation gap is positively related to the output gap according to

$$
\pi_{t+1}=\pi_{t}+\alpha y_{t}+\varepsilon_{t+1}
$$

where $\alpha>0$ and $\varepsilon_{t}$ is an i.i.d. supply shock with mean zero.

The output gap (or aggregate demand) is mean-reverting and negatively related to the ex-post real short interest rate following

$$
y_{t+1}=\beta y_{t}-\gamma\left(i_{t}-\pi_{t}\right)+\eta_{t+1}
$$

where $i_{t}$ is the deviation of the short interest rate (set by the central bank) from its long-term equilibrium level; $0<\beta<1 ; \gamma>0$; and $\eta_{t}$ is an i.i.d. demand shock with mean zero.

Our own contribution is to append a yield curve to this model. Bonds of different maturities are seen as imperfect substitutes, so the interest rate of maturity $n$ at time $t$ is set as an average of expected future short interest rates during the time to maturity plus a term premium,

$$
i_{t}^{n}=\frac{1}{n} \sum_{s=0}^{n-1} i_{t+s \mid t}+\xi_{t}^{n},
$$


where $i_{t+s \mid t}$ denotes the expectation as of period $t$ of the short interest rate $s$ periods ahead, and $\xi_{t}^{n}$ is the term premium at time $t$ for maturity $n$. Thus, in determining long rates, market participants will form (rational) expectations about the future path of the short central bank rate. ${ }^{4}$

Our choice of model requires some justification. Of course, relations (1) and (2) represent a highly stylized, and in some respects unrealistic, view of the macroeconomy. ${ }^{5}$ However, at this low level of complexity, it appears to be a close approximation to monetary policymakers' view of the world (see, e.g., Blinder, 1997). Also, the model fits the macroeconomic facts rather well (Rudebusch and Svensson, 1998). Finally, we are quite confident that our main insights are robust to reasonable extensions, most of which would entail the considerable cost of having to give up analytical methods for numerical analysis (Svensson, 1997a).

\subsection{The central bank problem}

At each instant, the central bank is assumed to select the short interest rate $i_{t}$ to minimize the intertemporal loss function

$$
\mathcal{L}_{t}=E_{t} \sum_{s=0}^{\infty} \delta^{s} L\left(\pi_{t+s}, y_{t+s}, \lambda_{t+s}\right),
$$

where $\delta$ is a discount factor and the period loss function $L(\cdot)$ is quadratic in deviations of the inflation and output gaps from their zero targets,

$$
L\left(\pi_{t}, y_{t}, \lambda_{t}\right)=\frac{1}{2}\left[\pi_{t}^{2}+\lambda_{t} y_{t}^{2}\right] .
$$

The parameter $\lambda_{t} \geq 0$ is the weight of output stabilization relative to inflation fighting at time $t$. The preferences of the central bank are assumed to be timevariant, following a martingale. Consequently, the expected value as of time $t$ of the preference parameter at any future period is equal to its current value;

$$
\lambda_{t+s \mid t}=\lambda_{t} \text { for all } s \geq 0,
$$

so any change in the preferences is seen as permanent. ${ }^{6}$ Since there is a one-to-one relationship between output and the short interest rate from equation (2), we follow

\footnotetext{
${ }^{4}$ In a similar fashion, Mellin (1997) adds a yield curve to a dynamic macroeconomic model to study the behavior of market interest rates. His basic model and purposes are different from ours, however.

${ }^{5}$ Natural extensions would be to include the long-term ex-ante real interest rate in the aggregate demand relationship instead of the short ex-post real rate; include forward-looking behavior; or consider time-varying parameters or target levels for inflation and output. (See also Svensson, 1997a.)

${ }^{6}$ The martingale assumption could possibly lead to negative realizations of $\lambda_{t}$. Assuming that its variance vanishes as $\lambda_{t}$ approaches zero, we can rule out such behavior.
} 
Svensson $(1997 \mathrm{a}, \mathrm{b})$ in treating the expected output gap $y_{t+1 \mid t}$ as the control variable and let the central bank solve the equivalent control problem

$$
V\left(\pi_{t+1 \mid t} ; \lambda_{t}\right)=\min _{y_{t+1 \mid t}}\left\{\frac{1}{2}\left[\pi_{t+1 \mid t}^{2}+\lambda_{t} y_{t+1 \mid t}^{2}\right]+\delta E_{t} V\left(\pi_{t+2 \mid t+1} ; \lambda_{t+1}\right)\right\},
$$

subject to

$$
\begin{aligned}
\pi_{t+2 \mid t+1} & =\pi_{t+1}+\alpha y_{t+1} \\
& =\pi_{t+1 \mid t}+\varepsilon_{t+1}+\alpha\left(y_{t+1 \mid t}+\eta_{t+1}\right) .
\end{aligned}
$$

Since $\lambda_{t}$ is an exogenous stochastic process with $\lambda_{t+s \mid t}=\lambda_{t}$, expected future values of the value function will be a function of $\lambda_{t}$ only, so

$$
E_{t} V\left(\pi_{t+2 \mid t+1} ; \lambda_{t+1}\right)=E_{t} V\left(\pi_{t+2 \mid t+1} ; \lambda_{t}\right)
$$

Therefore, at every period $t$ we can treat $\lambda_{t}$ as a given constant in the value function. After solving the control problem (7) subject to (8), the optimal short interest rate is backed out from the relationship

$$
y_{t+1 \mid t}=\beta y_{t}-\gamma\left(i_{t}-\pi_{t}\right)
$$

The first-order condition associated with (7) and (8) is

$$
\lambda_{t} y_{t+1 \mid t}+\alpha \delta E_{t} V_{\pi}\left(\pi_{t+2 \mid t+1} ; \lambda_{t}\right)=0
$$

Using the fact that the value function in (7) will be of the form

$$
V\left(\pi_{t+1 \mid t} ; \lambda_{t}\right)=k_{0}+\frac{1}{2} k_{t} \pi_{t+1 \mid t}^{2},
$$

where $k_{t}=k\left(\lambda_{t}\right)$ is given at $t$, together with equation (8) and the law of iterated expectations, yields the optimal expected output gap as a function of the expected inflation rate two periods ahead,

$$
y_{t+1 \mid t}=-\frac{\alpha \delta k_{t}}{\lambda_{t}} \pi_{t+2 \mid t},
$$

where the unique positive solution for $k_{t}$ is given by

$$
k_{t}=\frac{1}{2}\left[1-\frac{\lambda_{t}(1-\delta)}{\alpha^{2} \delta}+\sqrt{\left(1+\frac{\lambda_{t}(1-\delta)}{\alpha^{2} \delta}\right)^{2}+\frac{4 \lambda_{t}}{\alpha^{2}}}\right] \geq 1
$$

Details are given in Appendix A, following Svensson (1997a,b). 
Given the optimal $y_{t+1 \mid t}$ from (13), we can use (10) to back out the optimal interest rate as

$$
\begin{aligned}
i_{t}-\pi_{t} & =-\frac{1}{\gamma} y_{t+1 \mid t}+\frac{\beta}{\gamma} y_{t} \\
& =\frac{\alpha \delta k_{t}}{\gamma \lambda_{t}} \pi_{t+2 \mid t}+\frac{\beta}{\gamma} y_{t} .
\end{aligned}
$$

Leading (1) two periods and taking expectations gives

$$
\begin{aligned}
\pi_{t+2 \mid t} & =\pi_{t+1 \mid t}+\alpha y_{t+1 \mid t} \\
& =\pi_{t}+\alpha(1+\beta) y_{t}-\alpha \gamma\left(i_{t}-\pi_{t}\right)
\end{aligned}
$$

From (15) and (16) we then have

$$
\begin{aligned}
i_{t}-\pi_{t} & =\frac{\alpha \delta k_{t}}{\gamma \lambda_{t}} \pi_{t}+\frac{\beta \lambda_{t}+\alpha^{2} \delta k_{t}(1+\beta)}{\gamma \lambda_{t}} y_{t}-\frac{\alpha^{2} \delta k_{t}}{\lambda_{t}}\left(i_{t}-\pi_{t}\right) \\
& =A_{t} \pi_{t}+B_{t} y_{t}
\end{aligned}
$$

where

$$
\begin{aligned}
A_{t} & =A\left(\lambda_{t}\right)=\frac{\alpha \delta k_{t}}{\gamma\left(\lambda_{t}+\alpha^{2} \delta k_{t}\right)}>0 \\
B_{t} & =B\left(\lambda_{t}\right)=\frac{\beta}{\gamma}+\alpha A_{t}>0
\end{aligned}
$$

Thus, the optimal interest rate for the central bank is an increasing function of the current inflation and output gaps,

$$
i_{t}=\left(1+A_{t}\right) \pi_{t}+B_{t} y_{t}
$$

so the central bank follows a rule similar to that proposed by Taylor (1993).

Some features of the model and of the optimal policy response to supply and demand shocks may need some further consideration at this point. First, the model is formulated in deviations of inflation and output from their natural levels (normalized to zero for convenience), and so is the interest rate in equation (20). Therefore a negative shock to inflation or output will lead to negative values of the short interest rate. Second, since monetary policy affects inflation via output, and with a lag of two periods, the way to dampen the inflationary effects of a positive shock is to create a recession. In Appendix B we show that the response of the central bank to both inflation and output shocks is decreasing in the preference parameter $\lambda_{t}$. Thus, a central bank more prone to output stabilization will respond less to any shock. In particular, after a positive shock a central bank with a higher $\lambda_{t}$ will choose to 
create a smaller recession, regardless of whether the initial shock is to inflation or output.

\subsection{The term structure of interest rates}

Knowing the short rate at each point in time, it is now relatively straightforward to compute the economy's yield curve. The $n$-period interest rate is set as an average of future short rates, plus a term premium,

$$
i_{t}^{n}=\frac{1}{n} \sum_{s=0}^{n-1} i_{t+s \mid t}+\xi_{t}^{n}
$$

so we first need to find the expected path of future short rates in order to evaluate rates of longer maturities. Leading the interest rate rule (20) $s$ periods and taking expectations gives

$$
i_{t+s \mid t}=\left(1+A_{t}\right) \pi_{t+s \mid t}+B_{t} y_{t+s \mid t}
$$

since $A_{t}$ and $B_{t}$ are given at $t$. The expected output process $s \geq 1$ periods from now is obtained by leading (1) and (2), taking expectations, and using (22),

$$
\begin{aligned}
y_{t+s \mid t} & =\beta y_{t+s-1 \mid t}-\gamma\left(i_{t+s-1 \mid t}-\pi_{t+s-1 \mid t}\right) \\
& =-\gamma A_{t} \pi_{t+s-1 \mid t}+\left(\beta-\gamma B_{t}\right) y_{t+s-1 \mid t} \\
& =-\gamma A_{t} \pi_{t+s \mid t}
\end{aligned}
$$

The expected path of inflation for $s \geq 1$ periods into the future is then

$$
\begin{aligned}
\pi_{t+s \mid t} & =\pi_{t+s-1 \mid t}+\alpha y_{t+s-1 \mid t} \\
& =\left(1-\alpha \gamma A_{t}\right) \pi_{t+s-1 \mid t}
\end{aligned}
$$

and it is easily established by repeated substitution that expected inflation and output will follow the geometric series

$$
\pi_{t+s \mid t}=\left(1-\alpha \gamma A_{t}\right)^{s-1}\left[\pi_{t}+\alpha y_{t}\right]
$$

and

$$
y_{t+s \mid t}=-\gamma A_{t}\left(1-\alpha \gamma A_{t}\right)^{s-1}\left[\pi_{t}+\alpha y_{t}\right]
$$

Using these relations in (22), the expected future short interest rate $s$ periods ahead is given by

$$
i_{t+s \mid t}=\left[1+A_{t}\left(1-\gamma B_{t}\right)\right]\left(1-\alpha \gamma A_{t}\right)^{s-1}\left[\pi_{t}+\alpha y_{t}\right],
$$


and its sum is obtained, using the formula for geometric series, as

$$
\sum_{s=1}^{n-1} i_{t+s \mid t}=\left[1+A_{t}\left(1-\gamma B_{t}\right)\right] X_{t}^{n}\left[\pi_{t}+\alpha y_{t}\right]
$$

where

$$
X_{t}^{n}=\frac{1-\left(1-\alpha \gamma A_{t}\right)^{n-1}}{\alpha \gamma A_{t}} .
$$

Finally, using the interest rate rule (20) and the sum (28) in the definition (21), the market interest rate of maturity $n$ is given by

$$
i_{t}^{n}=\frac{1}{n}\left\{\left(1+A_{t}\right) \pi_{t}+B_{t} y_{t}+\left[1+A_{t}\left(1-\gamma B_{t}\right)\right] X_{t}^{n}\left[\pi_{t}+\alpha y_{t}\right]\right\}+\xi_{t}^{n} .
$$

As promised, this is our closed-form expression for the economy's yield curve.

\section{$3 \quad$ Policy and the term structure of interest rates}

We are now ready to examine how the term structure of interest rates is affected by monetary policy actions. From the central bank reaction function (20), we see that current monetary policy is entirely determined by current inflation, output, and the preferences of the central bank. Consequently, it is straightforward to separate endogenous monetary policy, responding to the development of inflation and output, from exogenous policy moves, due to shifts in the preference parameter $\lambda_{t}$.

In a first scenario, we examine how market interest rates vary when all parameters and shocks are symmetrically observed by all agents. In this scenario, interest rates respond to supply and demand shocks directly, with the magnitude depending on the central bank's preference parameter, since the response of the monetary authorities is perfectly predicted by market participants. The actual policy actions of the central bank then add no new information, and so will not affect the term structure of interest rates.

We next turn to a scenario where the central bank has access to advance information about either the supply or demand shock, or about its own preferences. In this case, the central bank's policy actions contain information about the unobservable variable. Consequently, interest rates will react to the actual policy moves, as market participants use this information to revise their beliefs about future monetary policy. Most importantly, the reaction of interest rates to endogenous policy is 
markedly different from the reaction to exogenous policy moves. ${ }^{7}$

All along, we will assume that the term premium is independent of all relevant variables, that is, that the expectations hypothesis of the term structure holds. ${ }^{8}$ This simplifying assumption serves to streamline the results below. In the empirical study of Section 4 we will see that certain policy moves in the U.S. have been followed by large shifts in the term premium, so we need to consider these cases separately.

\subsection{Symmetrically observed shocks}

When all variables are publicly observable, we see directly from equation (30) how market interest rates are affected by supply and demand shocks as well as by shifts in the preference parameter $\lambda_{t}$.

Differentiating equation (30) with respect to $\varepsilon_{t}$, the interest rate of maturity $n$ will respond to a supply shock according to

$$
\frac{d i_{t}^{n}}{d \varepsilon_{t}}=\frac{1}{n}\left\{1+A_{t}+\left[1+A_{t}\left(1-\gamma B_{t}\right)\right] X_{t}^{n}\right\} .
$$

Likewise, the interest rate will respond to a demand shock $\eta_{t}$ according to

$$
\frac{d i_{t}^{n}}{d \eta_{t}}=\frac{1}{n}\left\{B_{t}+\alpha\left[1+A_{t}\left(1-\gamma B_{t}\right)\right] X_{t}^{n}\right\} .
$$

Our first result is that these two derivatives are positive. When an inflationary shock (to supply or demand) hits the economy, the optimal response for the central bank is to increase its interest rate to squeeze out the effects on inflation and output. Since a monetary tightening reduces inflation by depressing output, the optimal response for the central bank is to only partially neutralize the shock in the first instant. Due to the persistence in the output and inflation processes, the economy will then be away from optimum for some time in the future. Hence, the expected path of future short rates is also revised upwards, but with declining magnitude. Under perfect information, this behavior of the central bank is accurately predicted by market

\footnotetext{
${ }^{7}$ Note that in this private information setting, market interest rates respond only to the unanticipated component of monetary policy. Our terminology may be slightly confusing: endogenous and exogenous policy moves do not coincide with anticipated and unanticipated policy, respectively. We refer to endogenous policy as responding to information (possibly private) about the economy, and exogenous policy as independent of the economic development and due to central bank preference shifts.

${ }^{8}$ While we agree that the term premium could vary in a systematic way with inflation, output, or the monetary policy stance, it is noteworthy that a noisy term premium coupled with active monetary policy may account for some of the alleged empirical failures of the expectations hypothesis (see Mankiw and Miron, 1986, and McCallum, 1994).
} 
participants, and interest rates of all maturities increase as a response to a positive supply or demand shock.

This is the intuition underlying our first result:

Proposition 1 Interest rates of all maturities are positively related to both supply and demand shocks, with the magnitude diminishing with maturity. Thus all interest rates (including the central bank rate) move in the same direction in response to a shock.

\section{Proof See Appendix C.1.}

This result seems quite intuitive, but it turns out not to be as straightforward as it looks. One would expect the central bank to react to an inflationary shock by raising the current and all future interest rates, letting the effect die out as the future gets more distant. This turns out not to be the case, however. From (27), future short interest rates are given by

$$
i_{t+s \mid t}=\left[1+A_{t}\left(1-\gamma B_{t}\right)\right]\left(1-\alpha \gamma A_{t}\right)^{s-1}\left[\pi_{t}+\alpha y_{t}\right],
$$

so since $0<\alpha \gamma A_{t} \leq 1$, the direction of the reaction of future short rates to a shock is determined by the term $\left[1+A_{t}\left(1-\gamma B_{t}\right)\right]$. This expression is not necessarily positive; for a sufficiently large value of $A_{t}$ (i.e., a small value of $\lambda_{t}$, see Appendix B) it could be negative, depending on parameter values. If so, a sufficiently inflationaverse central bank will react very strongly to any shock, creating a large recession to wipe out the inflationary effects of the shock (since the effect on inflation goes via output). In future periods, when the inflation rate is back to more normal levels, the central bank will turn its attention to the output gap, and will lower the interest rate to a level below the initial rate, and then slowly raise the rate back toward the initial level. Nevertheless, despite this anomalous response of the central bank, long rates will always react positively to the initial policy action, since the large response in the first period will dominate the negative response in future periods. ${ }^{9}$

A second implication of the model is that the response of all interest rates to a shock is linear, since the terms on the right-hand sides of (31) and (32) are constant, for a given $n$. Consequently, the relationship between any two interest rates will also be linear.

It is interesting to see how the magnitude of the preference parameter $\lambda_{t}$ affects the response of interest rates to a given shock. As $\lambda_{t}$ increases, the central bank becomes less inflation-averse, and more prone to stabilizing output. For a given shock,

\footnotetext{
${ }^{9}$ Of course, if the central bank is also concerned with smoothing interest rates, or takes parameter uncertainty into account, such odd policy responses could be excluded. (See, e.g., Söderström, 1999b.)
} 
the optimal interest rate policy is less fierce, and the central bank rate is changed by a smaller amount, since both $A_{t}$ and $B_{t}$ are decreasing in $\lambda_{t}$ (see Appendix B). In the long run, however, a given shock will remain for longer in the economy, so future short rates are expected to be higher than if the central bank had neutralized a larger portion of the shock in the initial move. Therefore, central banks with a larger value of $\lambda_{t}$ will see a larger effect on long rates for a given shock, since the central bank rate is expected to differ from the initial level for a longer period of time.

This mechanism lies behind our second result:

Proposition 2 With a higher value of $\lambda_{t}$, short interest rates respond less and long interest rates respond more to a given shock. Consequently, long rates respond more to a given change in short rates.

Proof See Appendix C.2.

We can now summarize our first set of results. When all shocks are observable to all agents, all interest rates move in the same direction in response to a shock that leads the public to revise their expectations of future monetary policy. For a more inflation-averse central bank, short rates will respond more, but long rates less to a given shock.

Note that in this scenario, market interest rates do not respond to the monetary policy actions per se, since these are perfectly anticipated, and thus already priced into the market. The way we have chosen to model it, the central bank responds instantaneously to new information, and the above distinction is purely notional. In a more realistic setting, the central bank would respond to new information with a lag, and possibly at certain fixed intervals. Then the distinction between interest rate reactions to shocks and the reaction to policy actions becomes important, especially when interpreting the theoretical results empirically.

\subsection{Asymmetric information}

For efficient bond markets to respond to the actual policy moves of the central bank, these moves must contain some information not previously available to market participants. Or, in other words, the central bank must have access to private information about relevant variables in the economy. In our model, this information can be of two kinds: information about shocks to the inflation or output paths, or information about the central bank's preferences. We will study the two kinds 
of central bank private information separately, to see how the presence of private information affects the determination of interest rates.

We begin by considering the case where the central bank has private (or advance) information about the current realization of the supply or the demand shock. ${ }^{10}$ If only one of the shocks is unobservable at a time, the realization of this shock is easily inferred by market participants after observing the reaction of the central bank by inverting the policy rule (20). ${ }^{11}$ Thus, when the current realization of the supply shock $\varepsilon_{t}$ is unobservable, it is inferred as

$$
\hat{\varepsilon}_{t}\left(i_{t}\right)=\frac{1}{1+A_{t}} i_{t}-\left(\pi_{t-1}+\alpha y_{t-1}\right)-\frac{B_{t}}{1+A_{t}} y_{t},
$$

where all variables on the right-hand side are observable at time $t$. Similarly, when the central bank has private information about the demand shock $\eta_{t}$, its current realization is inferred as

$$
\hat{\eta}_{t}\left(i_{t}\right)=\frac{1}{B_{t}} i_{t}-\frac{1+A_{t}}{B_{t}} \pi_{t}-\left[\beta y_{t-1}-\gamma\left(i_{t-1}-\pi_{t-1}\right)\right] .
$$

In this simplistic setup, when the realization of the unobservable shock is perfectly inferred by bond markets, the results from the previous section remain. Now, however, market interest rates will react to the policy actions of the central bank, since these reveal information about the realized shocks, and thus about the future path of monetary policy. Consequently, although the results below are simple corollaries of Propositions 1 and 2 above, they have quite distinct interpretations for the response of interest rates to monetary policy.

First, when the supply or demand shock is unobservable to the public, Proposition 1 implies that all interest rates will move in the same direction as the central bank rate, as market participants infer the realization of the unobservable shock:

Proposition 3 When the central bank has private information about either the supply or the demand shock, market interest rates will be positively related to the central bank rate. This relationship becomes weaker as the interest rate's maturity increases.

\footnotetext{
${ }^{10}$ This may not be an innocent assumption, and deserves some closer attention. Recently, Romer and Romer (1996) have suggested the presence of central bank private information as an explanation for the positive relationship between the central bank rate and long-term interest rates. In an empirical test, they found strong support for their hypothesis: the Federal Reserve's inflation forecasts are quite superior to those of private forecasters, and private forecast errors can be explained to a large part by the Fed's own forecasts. Also, there are some signs that private forecasters use Fed policy to revise their own forecasts. The authors conclude that the Federal Reserve has access to more (or better) information than the public, although this could be due to better and more extensive data processing on the part of the Fed.

${ }^{11}$ We thus do not have a proper signal extraction problem for private agents. We choose to concentrate on the simple perfect-inference case here, to illustrate our mechanisms in a transparent way.
} 


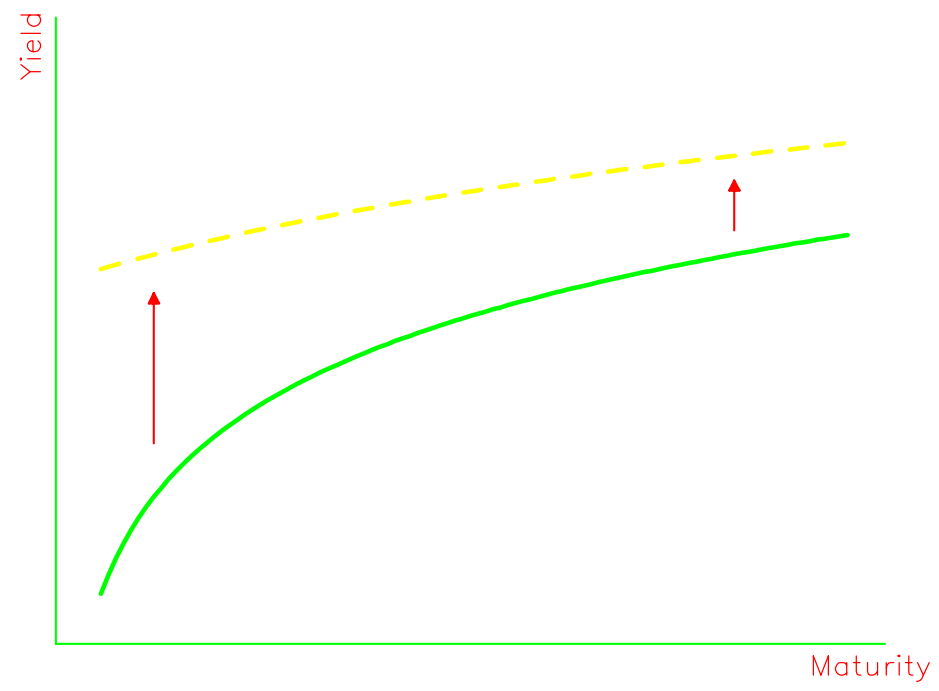

Figure 1: Yield curve response to an endogenous policy contraction.

Proof Follows immediately from Proposition 1.

A graphical representation of this result is given in Figure 1. A monetary tightening leads the public to infer that a positive inflationary shock has hit the economy, and the entire yield curve shifts upwards, with the reaction decreasing with maturity. For a surprise expansion of policy, the reaction is the opposite.

Most interesting, however, is the response of interest rates to an unexpected shift in the preferences of the central bank. We now assume that all shocks are observable, but that the current value of the preference parameter $\lambda_{t}$ is known only to the central bank itself. After a given shock has hit the economy, the public expects the central bank to act according to the rule (20), given their belief about the parameter $\lambda_{t}$. Any unexpected policy response is then interpreted as a (permanent) change in $\lambda_{t}$, leading the public to revise their expectations about the future path of the central bank rate.

Since a central bank with a lower value of $\lambda_{t}$ will set a higher interest rate (in absolute terms) for a given shock, but keep the interest rate away from the initial level for a shorter period of time, an unexpectedly large tightening leading to a revision downwards in the public's perception of $\lambda_{t}$ will lead to rising short rates but falling long interest rates. This is the basic intuition behind our final result:

Proposition 4 When the central bank's preferences are unobservable to the public, long interest rates will move in the opposite direction to the innovation in the central bank rate. Thus, the yield curve will tilt as a response to unexpected monetary policy: 


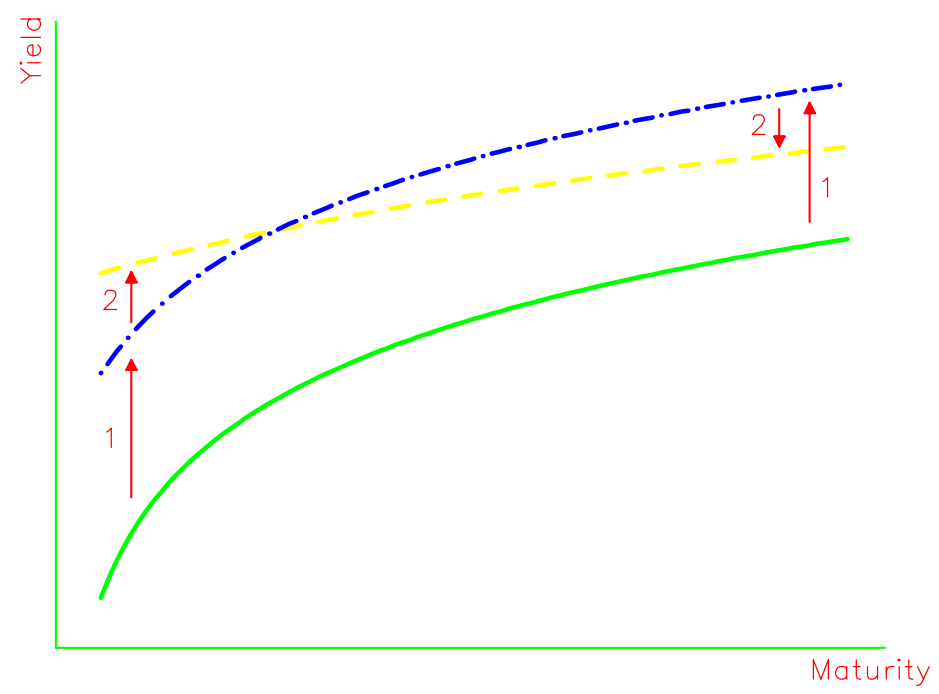

Figure 2: Yield curve response to an exogenous policy contraction.

an unexpectedly high central bank rate tilts the yield curve clockwise; an unexpectedly low rate tilts it counter-clockwise.

\section{Proof See Appendix C.3.}

This response is shown in Figure 2. When a positive shock realizes, the yield curve shifts up in anticipation of the central bank's response (1). If the central bank acts as expected, market interest rates will not move at all when the central bank rate is adjusted. If, however, the central bank sets a higher interest rate than was expected, the public realizes that the bank has become more inflation averse (i.e., $\lambda_{t}$ has decreased). Then short rates rise, but longer rates fall, leading to a clockwise tilt of the yield curve (2). Similarly, if the central bank responds with a lower rate than expected, the yield curve tilts counter-clockwise.

\subsection{Empirical interpretation}

In the model, the central bank adjusts its interest rate in every period, as new information about the economy is revealed. In reality, central banks adjust their monetary policy stance at discrete intervals, after accumulating a sufficient amount of information. Consequently, when translating our results to empirically testable hypotheses, we need to separate days on which the central bank does not intervene from days on which it does.

On days when the central bank rate is left unchanged, the information revealed predominantly concerns the state of the economy, and since no information is re- 
vealed from the central bank's policy moves, this information is symmetrically observed. Consequently, Propositions 1 and 2 should be expected to hold on days when the central bank does not intervene: interest rates should move in the same direction (Proposition 1), and more inflation-averse central banks should see short interest rates respond more but long rates less to new information, so that the relationship between long and short rates should be weaker (Proposition 2).

On days when the central bank does act to change its interest rate instrument, however, its private information may be revealed. Then Proposition 3 predicts that if the central bank action reveals information about the economy, all interest rates should move in the same direction, with long rates reacting less than short rates, while Proposition 4 implies that on occasions when the central bank move reveals information about the bank's preferences, short and long rates should move in opposite directions.

In their study of the 1974-79 funds rate targeting regime in the U.S., Cook and Hahn (1989) show that when the Fed moved its target level for the federal funds rate, interest rates of all maturities on average moved in the same direction as the target. Interpreting this finding, and similar results for other countries, ${ }^{12}$ in the light of our model indicates that monetary policy actions are driven more often by economic developments than by preference shifts. Skinner and Zettelmeyer (1995) present results that lend support to Proposition 2: long interest rates respond more to short rates in the U.S. and the U.K. than in Germany and France. Accepting the hypothesis that the central banks of Germany and France are more inflation-averse than the Federal Reserve and the Bank of England, this is exactly what our model would predict.

In the following section, we will complement these results with our own empirical evidence, testing our theoretical implications more directly.

\section{The response of interest rates to monetary policy}

To test our theoretical predictions, we need to separate policy shifts driven by new information (endogenous policy) from shifts driven by changes in the central bank's preferences (exogenous policy). Here, we are primarily interested in bond markets' perception of monetary policy, since interest rates set on financial markets reflect

\footnotetext{
${ }^{12}$ See Battelino et al. (1997) for Australia; Buttiglione et al. (1997) for Italy; Lindberg et al. (1997) for Sweden; and Skinner and Zettelmeyer (1995) for France, Germany, the U.K., and the U.S.
} 
investors' perceptions about central bank policy rather than the central bank's 'true' policy strategies.

We attempt to extract such monetary policy perceptions from U.S. bond markets by studying the commentaries in the 'Credit Markets' column of the Wall Street Journal on days surrounding changes in the Federal Reserve's target level for the federal funds rate in the period from October 1988 to May 1997. On any day, the Wall Street Journal interviews a number of bond traders, analysts, and economists for comments about important events concerning the bond markets. A sample of these comments, along with the journalist's own analysis, is then reported in the Journal. Since Fed policy moves are crucial for the development of financial markets, and especially for the bond market, the news of a change in the monetary policy stance typically dominates the commentaries on days following a Fed move.

Even though the comments after a policy move by the Fed are surprisingly homogeneous, any move will typically be interpreted as revealing information both about the economic development and about the Fed's preferences. For simplicity, we will concentrate on finding the dominant factor behind each move; thus our classification is a rough description of the faceted interpretations of the policy adjustments. ${ }^{13}$

We then proceed by analyzing the response of market interest rates to monetary policy, as measured by the one-day change in the 3-month treasury bill rate. The 3 -month rate is sufficiently short to be mainly determined by current and expected future policy actions, but of sufficiently long maturity to avoid noise from expectation errors due to the exact timing of Fed actions. ${ }^{14}$ On trading days when the Fed leaves its target level for the federal funds rate unchanged, the change in the 3 -month rate is interpreted as a measure of expected future changes in the Fed's policy stance in response to new information on that day. On days when the funds rate target level is adjusted, any movement in the 3-month rate is, as a first approximation, interpreted as the surprise element of the policy action, that is, the policy innovation. Thus we can compare the response of market interest rates to policy

\footnotetext{
${ }^{13}$ This problem of mixed events is likely to be most serious for events classified as exogenous, since on these days, some information about economic developments is also likely to be released. Therefore we will attempt to distill the interest rate response to the 'true' exogenous component from these policy shifts by controlling for the typical non-policy event.

${ }^{14}$ Using a shorter rate as a measure of policy (e.g., the innovation in the funds rate target) is problematic if bond markets anticipate the size of a policy move correctly, but not the actual timing of policy. The measured policy innovation then overestimates the true innovation. Harvey and Huang (1994) present evidence that markets are better at predicting the direction of Fed actions than their timing. Also, as shown by Söderström (1999a), market expectations of Fed policy extracted from the federal funds futures market vary systematically across months and trading days, and thus are less reliable as measures of the expected component of policy moves.
} 
innovations on exogenous and endogenous policy days, and also compare with days when the Fed has left its funds rate target unchanged, but new information has led bond markets to update their expectations of Fed policy.

The length of the sample period is due to changes in the operating procedures of U.S. monetary policy during the 1980s. Although the Federal Reserve returned to targeting the federal funds rate in late 1982, not until late 1988 was the targeting sufficiently strict for financial market participants to rely on funds rate observations to identify changes in the monetary policy stance. Target changes before 1988 were hardly ever noticed by market participants, unless accompanied by a change in the published discount rate. ${ }^{15}$

\subsection{Classification of monetary policy events}

From October 1988 to May 1997 the Federal Reserve changed its target level for the federal funds rate on 47 occasions, as reported by Rudebusch (1995) for 1988-92 and the Federal Reserve Bank of New York for 1993-97. ${ }^{16}$ Since our methodology of classifying monetary policy events is new, we need to explain in more detail the criteria used.

Typical comments in the Wall Street Journal of cases being interpreted as exogenous, or based on a change in preferences, are: “. . . there was some disappointment that the Federal Reserve didn't signal a larger cut in the rate," from December 20, 1990, or: "This rate cut says the Fed is likely to be more aggressive cutting rates than people thought'..." in the commentary of February 2, 1996. An especially clear report comes after the target cut of April 30, 1991, when the Journal reports that: "... [the move] didn't follow any major economic report...," indicating that the cut was not based on any new information, but continues by quoting an analyst saying that the move "... smacks of some political pressure on the Fed," since it had come shortly after the Bush administration had argued for global interest-rate cuts.

As for the events interpreted as endogenous responses to the economic development, typical comments are: "The U.S. Federal Reserve's latest move to cut interest rates reflects its uneasiness about the slow growth of money supply and the disappointingly torpid economic recovery," from September 16, 1991, or: “...the Fed's

\footnotetext{
${ }^{15}$ Below we will see that also during 1988 and 1989 many of the changes in the funds rate target passed unnoticed by financial market participants.

${ }^{16}$ Roley and Sellon (1996) argue that some of the target changes reported by Rudebusch do not correspond to actual decisions to change policy. Since some of these cases were apparently noticed by market participants (see the full classification in Appendix D), we choose to use the Rudebusch series.
} 
decision to cut rates. . came primarily for concerns about recent contractions in the U.S. money supply," on April 10, 1992. On some occasions, mostly during the later period of our sample, the Fed announced its target change, accompanied by its own comments about the factors underlying the change. An example is December 20, 1995, when the Journal writes: "The Fed said that "inflation has been somewhat more favorable than anticipated...'." Unless there are other signs of the opposite, these events are also classified as endogenous. Finally, a peculiar, but for our purposes very encouraging, case is July 7, 1995, when the Journal speculates that the Fed had access to information in the employment report before the report was published: “. . the Fed's willingness to ease ahead of Friday's data suggests that the central bank is looking for a weak employment report."

In ten cases, mostly during 1988 and 1989, the Journal makes no mention of the policy move, leading us to conclude that market participants never noticed the change in the funds rate target. These cases are omitted from the sample of target changes, and treated as non-policy days. ${ }^{17}$ On seven occasions, the monthly employment report from the Bureau of Labor Statistics was released on the same day as the policy move, so we cannot separate the effects on financial markets of the information release from the effects of policy. Consequently, these cases are also treated as non-policy days. ${ }^{18}$

Of the remaining 30 events of policy changes, on two occasions (January 9, 1991, and October 31, 1991) the change in the funds rate target was noticed by financial market participants on the day before the actual target change reported by Rudebusch. On these occasions we choose to use the interest rate response of the day preceding the reported target change, when the information seems to have reached the markets.

Of these 30 events, 19 were classified as endogenous responses to the state of the economy, and 11 as caused by exogenous changes of the Fed's preferences. Table 1

\footnotetext{
${ }^{17}$ During this early part of the sample, the Fed did not target the funds rate very closely. From 1990 on, target changes reported by the Federal Reserve Bank of New York are always attributed to one particular day. During 1988 and 1989, however, the Fed often reports gradual changes in the target, over several weeks or months. It is then not surprising that many of these changes were not noticed by market participants on the exact day reported by Rudebusch (1995).

${ }^{18}$ Naturally, there is some information in the data for these days also. The problem is that when estimating the policy innovation with the 3 -month rate, there is always some measurement error, and on days when other significant information is released on the same day as monetary policy is adjusted, this measurement error is expected to be very large. Therefore we choose not to use these observations. That the employment report is important for the conduct of monetary policy is obvious from the newspaper commentaries. For some empirical evidence, see Cook and Korn (1991) or Balduzzi et al. (1997).
} 
Table 1: Summary of classification

\begin{tabular}{llll}
\hline \hline Endogenous & Exogenous & Report & Unnoticed \\
\hline Dec 15, 1988 & Jan 5, 1989 & Dec 7, 1990 & Oct 20, 1988 \\
Feb 23, 1989 & Feb 14, 1989 & Feb 1, 1991 & Nov 17, 1988 \\
Jun 6, 1989 & Feb 24, 1989 & Mar 8, 1991 & Nov 22, 1988 \\
Jul 7, 1989 & Dec 20, 1989 & Dec 6, 1991 & Dec 29, 1988 \\
Jul 27, 1989 & Jul 13, 1990 & Jul 2, 1992 & Feb 9, 1989 \\
Oct 29, 1990 & Dec 19, 1990 & Sep 4, 1992 & May 4, 1989 \\
Jan 8, 1991 & Apr 30, 1991 & Feb 4, 1994 & Aug 10, 1989 \\
Aug 6, 1991 & May 17, 1994 & & Oct 18, 1989 \\
Sep 13, 1991 & Aug 16, 1994 & & Nov 6, 1989 \\
Oct 30, 1991 & Nov 15, 1994 & & \\
Nov 6, 1991 & Jan 31, 1996 & & \\
Dec 20, 1991 & & & \\
Apr 9, 1992 & & & \\
Mar 22, 1994 & & & \\
Apr 18, 1994 & & & \\
Feb 1, 1995 & & & \\
Jul 6, 1995 & & & \\
Dec 19, 1995 & & & \\
Mar 25, 1997 & & & \\
\hline
\end{tabular}

Classification of 47 changes in the federal funds rate target October 3, 1988-May 30, 1997.

summarizes the classification. A detailed description of all events, with the relevant quotes from the Wall Street Journal, is found in Appendix D.

We end this section by stressing that the classification presented here should be seen as tentative. Due to data collection costs, we have limited ourselves to one source of information, and although we believe the Wall Street Journal to be one of the most natural places to begin, the information collected is by no means complete. We therefore welcome any efforts to improve upon our classification.

\subsection{Empirical results}

Daily data on interest rates from October 3, 1988, to May 30, 1997, are taken from the FRED database of the Federal Reserve Bank of St. Louis. Short-term interest rates (3-month, 6-month, and 1-year rates) are treasury bill rates from the secondary market, and long-term interest rates (of 2, 3, 5, 7, 10, and 30 years' maturity) are treasury bond rates of constant maturity. The data for the 47 policy days are reported in Appendix E.

Using these data, we want to estimate how market interest rates move both in response to actual Fed policy moves and in anticipation of Fed reactions to new 
information. We thus want to estimate a regression like

$$
\Delta i_{t}^{n}=\alpha_{n}+\left(\beta_{n}^{\mathrm{NP}} d_{t}^{\mathrm{NP}}+\beta_{n}^{\mathrm{End}} d_{t}^{\mathrm{End}}+\beta_{n}^{\mathrm{Ex}} d_{t}^{\mathrm{Ex}}\right) \Delta i_{t}^{3 \mathrm{~m}}+v_{t}^{n},
$$

where $\Delta i_{t}^{n}$ is the change in the $n$-maturity interest rate on day $t ; \Delta i_{t}^{3 \mathrm{~m}}$ is the corresponding change in the 3-month rate, that is, our measure of policy innovations; and $d_{t}^{j}$ is a dummy taking the value one if day $t$ belongs to group $j$ and zero otherwise.

To the group NP (non-policy) belong all days when the Fed has left its funds rate target unchanged. On these days, the 3-month rate moves in anticipation of future Fed policy reactions to information released on day $t$, and longer interest rates may respond to this policy innovation. The group End corresponds to policy days classified as endogenous, and Ex are exogenous policy days. The obtained estimates of $\beta_{n}^{j}$ are thus the estimated responses of the $n$-maturity interest rate to a policy innovation of type $j$.

According to our theoretical analysis, equation (36) is the correct empirical specification given that the term premium $\xi_{t}^{n}$ and the taste parameter $\lambda_{t}$ are constant. Of course, both of these vary in practice. To take account of variations in the term premium, we have looked in our case material for statements concerning changes in interest rate uncertainty. As it happens, two events stand out; May 17 and August 16, 1994. On these occasions, the reports from the Wall Street Journal make clear that the Fed's actions considerably reduced the uncertainty concerning the future path of policy. In other words, these moves seem to have been followed by large reductions in the term premium. ${ }^{19}$ To control for these movements in the term premium, we include an intercept dummy for each of these events.

Permanent changes in the taste parameter $\lambda_{t}$ are more difficult to handle. Since our model allows shocks to $\lambda_{t}$, and we identify such shocks empirically, there might in principle be a time subscript on each of our slope parameters in equation (36). Given the small number of policy events in our sample, we have chosen to ignore this issue.

Before resorting to statistical methods, let us eyeball some of the data. Figures 3-5 show scatter plots of the change in the 10-year rate against the change in the 3 -month rate on policy days. Figure 3 shows the relationship for all 30 policy events, and Figures 4 and 5 break up the relationship into endogenous and exogenous events. In Figure 3 there is a clear positive relationship between the long rate response and the policy innovation, although there are some odd observations. For the endogenous events in Figure 4, the positive correlation is obvious, whereas the

\footnotetext{
${ }^{19}$ This is also consistent with other analyses of Fed policy during 1994, e.g., Campbell (1995).
} 


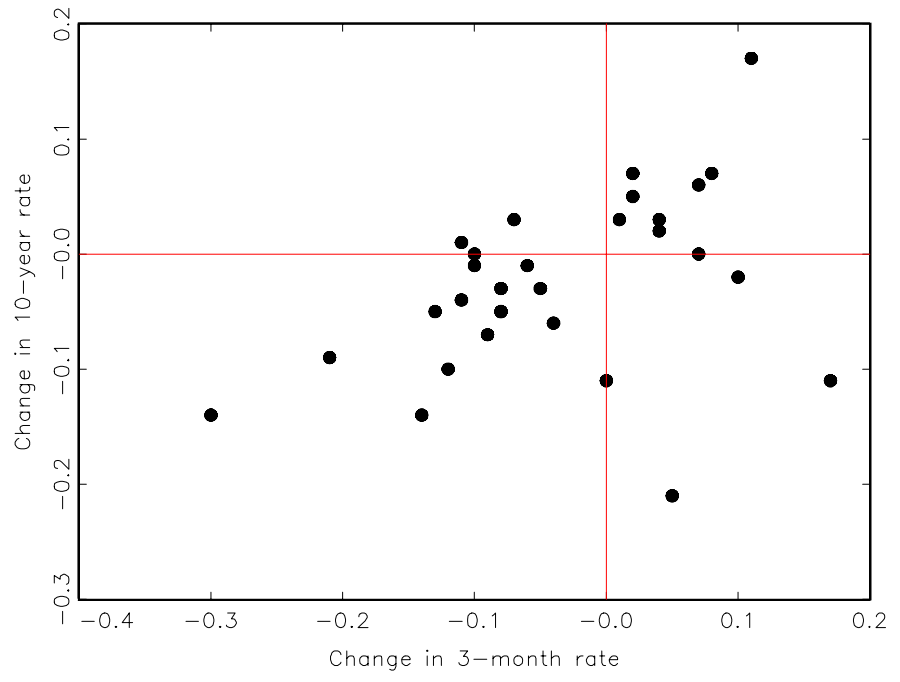

Figure 3: Response of the 10-year interest rate to a change in the 3-month rate: 30 classified policy events

exogenous events in Figure 5 show a more ambiguous picture. The two observations from May and August 1994 also stand out clearly in the scatter plots.

The regression we end up estimating then is

$$
\begin{aligned}
\Delta i_{t}^{n} & =\alpha_{n}+\left(\beta_{n}^{\mathrm{NP}} d_{t}^{\mathrm{NP}}+\beta_{n}^{\mathrm{End}} d_{t}^{\mathrm{End}}+\beta_{n}^{\mathrm{Ex}} d_{t}^{\mathrm{Ex}}\right) \Delta i_{t}^{3 \mathrm{~m}} \\
& +\gamma_{n}^{9405} d_{t}^{9405}+\gamma_{n}^{9408} d_{t}^{9408}+v_{t}^{n}
\end{aligned}
$$

where $d_{t}^{9405}$ and $d_{t}^{9408}$ are intercept dummies for the events of May and August 1994. The main hypothesis to be examined is that long-term interest rates respond positively to endogenous policy moves but negatively to exogenous moves:

Hypothesis 1 For large $n, \beta_{n}^{\mathrm{Ex}}<0<\beta_{n}^{\text {End }}$.

The discussion in Section 3.3 also leads us to test the hypothesis that all rates respond similarly (positively) to endogenous policy innovations as to the information released on non-policy days:

Hypothesis $2 \beta_{n}^{\mathrm{NP}}=\beta_{n}^{\text {End }}>0$ for all $n$.

And finally, our theoretical model predicts that for all maturities, the response falls with maturity:

Hypothesis $3 \beta_{n}^{j}$ is decreasing in $n$ for all $j$. 


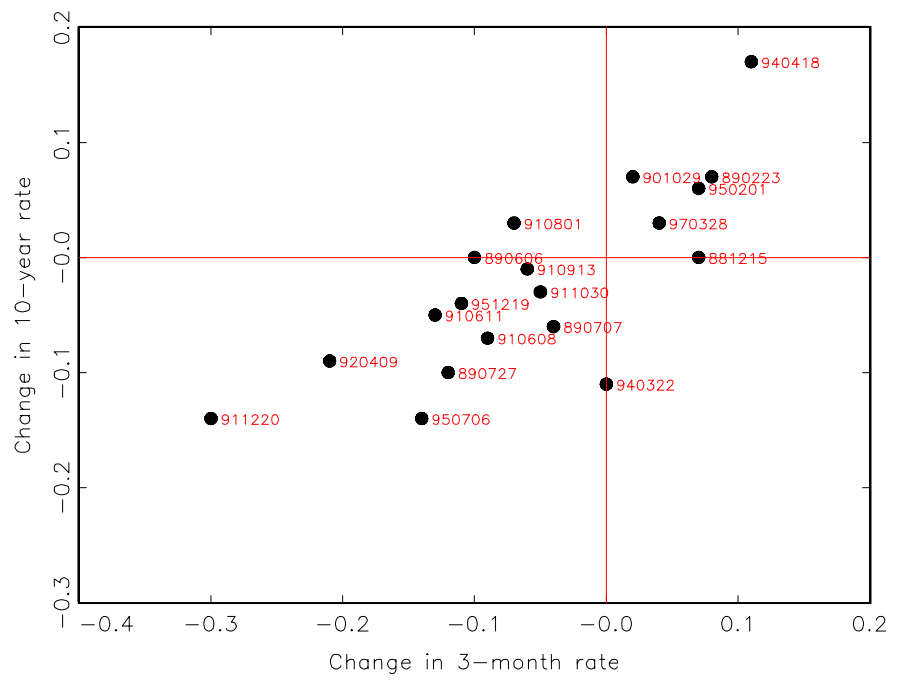

Figure 4: Response of the 10-year interest rate to a change in the 3-month rate: endogenous policy events

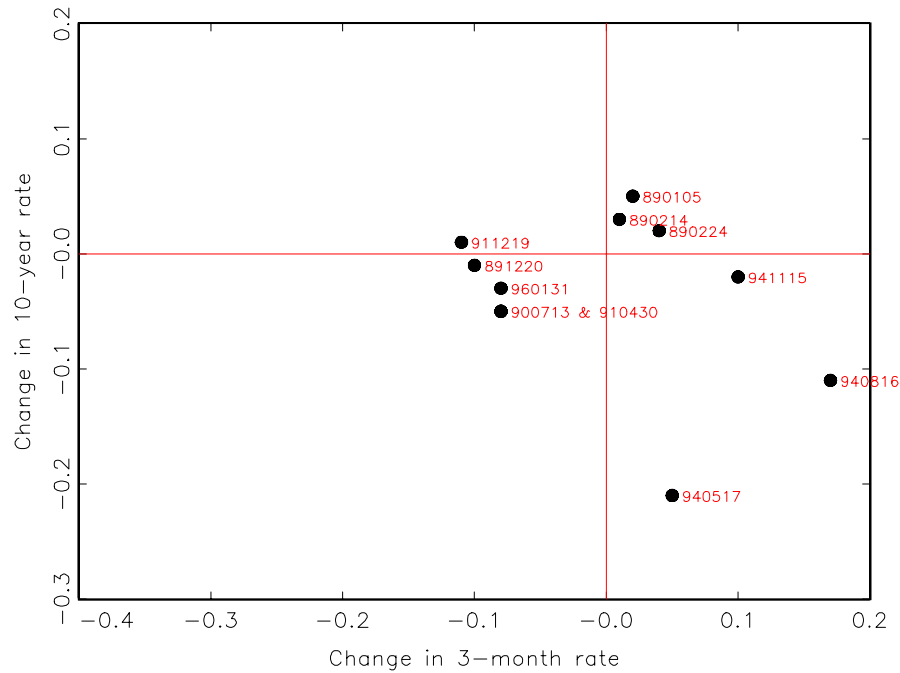

Figure 5: Response of the 10-year interest rate to a change in the 3-month rate: exogenous policy events 
Table 2: Interest rate response to a policy innovation

\begin{tabular}{|c|c|c|c|c|c|c|c|c|}
\hline & 6 months & 1 year & 2 years & 3 years & 5 years & 7 years & 10 years & 30 years \\
\hline \multirow[t]{2}{*}{$\alpha_{n}$} & 0.000 & 0.000 & 0.000 & 0.000 & 0.000 & -0.000 & -0.000 & -0.000 \\
\hline & $(0.001)$ & $(0.001)$ & $(0.001)$ & $(0.001)$ & $(0.001)$ & $(0.001)$ & $(0.001)$ & $(0.001)$ \\
\hline \multirow[t]{2}{*}{$\beta_{n}^{\mathrm{NP}}$} & $0.808^{* *}$ & $0.773^{* *}$ & $0.832^{* *}$ & $0.787^{* *}$ & $0.722^{* *}$ & $0.621^{* *}$ & $0.557^{* *}$ & $0.426^{* *}$ \\
\hline & $(0.024)$ & $(0.032)$ & $(0.039)$ & $(0.040)$ & $(0.039)$ & $(0.037)$ & $(0.035)$ & $(0.032)$ \\
\hline \multirow[t]{2}{*}{$\beta_{n}^{\text {End }}$} & $0.971^{* *}$ & $0.953^{* *}$ & $0.945^{* *}$ & $0.860^{* *}$ & $0.730^{* *}$ & $0.616^{* *}$ & $0.554^{* *}$ & $0.419^{* *}$ \\
\hline & $(0.055)$ & $(0.074)$ & $(0.099)$ & $(0.112)$ & $(0.105)$ & $(0.094)$ & $(0.080)$ & $(0.069)$ \\
\hline \multirow[t]{2}{*}{$\beta_{n}^{\mathrm{Ex}}$} & $1.150^{* *}$ & $0.967^{* *}$ & $0.838^{* *}$ & $0.542^{* *}$ & $0.465^{* *}$ & $0.316^{*}$ & 0.194 & 0.002 \\
\hline & $(0.133)$ & $(0.138)$ & $(0.116)$ & $(0.105)$ & $(0.096)$ & $(0.134)$ & $(0.127)$ & $(0.137)$ \\
\hline$\gamma_{n}^{9405}$ & $\begin{array}{c}-0.108^{* *} \\
(0.007)\end{array}$ & $\begin{array}{c}-0.158^{* *} \\
(0.007)\end{array}$ & $\begin{array}{c}-0.192^{* *} \\
(0.006)\end{array}$ & $\begin{array}{c}-0.197^{* *} \\
(0.005)\end{array}$ & $\begin{array}{c}-0.213^{* *} \\
(0.005)\end{array}$ & $\begin{array}{c}-0.246^{* *} \\
(0.007)\end{array}$ & $\begin{array}{c}-0.219^{* *} \\
(0.007)\end{array}$ & $-0.190^{* *}$ \\
\hline$\gamma_{n}^{9408}$ & $\begin{array}{c}-0.176^{* *} \\
(0.023)\end{array}$ & $\begin{array}{c}-0.175^{* *} \\
(0.023)\end{array}$ & $\begin{array}{c}-0.193^{* *} \\
(0.020)\end{array}$ & $\begin{array}{c}-0.152^{* *} \\
(0.018)\end{array}$ & $\begin{array}{c}-0.179^{* *} \\
(0.016)\end{array}$ & $\begin{array}{c}-0.174^{* *} \\
(0.023)\end{array}$ & $\begin{array}{c}-0.143^{* *} \\
(0.022)\end{array}$ & $\begin{array}{c}-0.120^{* *} \\
(0.023)\end{array}$ \\
\hline $\bar{R}^{2}$ & 0.643 & 0.491 & 0.372 & 0.327 & 0.278 & 0.226 & 0.201 & 0.151 \\
\hline$\beta_{n}^{\mathrm{NP}}=\beta_{n}^{\text {End }}$ & $7.446^{* *}$ & $4.941^{*}$ & 1.144 & 0.373 & 0.005 & 0.003 & 0.002 & 0.009 \\
\hline$\beta_{n}^{\text {End }}=\beta_{n}^{\text {Ex }}$ & 1.561 & 0.008 & 0.498 & $4.302^{*}$ & $3.501^{\circ}$ & $3.397^{\circ}$ & $5.802^{*}$ & $7.438^{* *}$ \\
\hline
\end{tabular}

OLS estimation of equation (37) on daily observations from October 3, 1988, to May 30, 1997. Wald-tests $\left(\chi^{2}\right)$ with 1 degree of freedom. White (1980) standard errors in parentheses, ${ }^{* *} /{ }^{*} /{ }^{\circ}$ denote significance at the $1 \%^{-}, 5 \%^{-}$, and $10 \%$-level, respectively.

Table 2 reports OLS estimates from equation (37). ${ }^{20}$ The estimated intercept term is virtually zero, as expected, and our last two hypotheses are clearly confirmed: the slope coefficients for the non-policy and endogenous policy events are large and strongly significant for all maturities (the two responses cannot be statistically separated for maturities of two years and above), and for all groups, the response falls with maturity. ${ }^{21}$

We then turn to our main hypothesis. For the exogenous events, the estimated slope coefficients are positive, but not significantly different from zero for the longest maturities, and virtually zero for the 30-year rate. The reported Wald statistics reject the hypothesis of equal coefficients for the endogenous and exogenous events at the 10\%-level for maturities of three years and above. Long interest rates thus

\footnotetext{
${ }^{20}$ To test the econometric specification, we also estimated regressions including squared independent variables. The squared change in the 3 -month rate is occasionally significant, but adds nothing to the explanatory power of the model. The model easily passes a number of other specification tests: when the term premium dummies are included, error terms are normally distributed and autocorrelation is not a problem. The test statistics are omitted for brevity.

${ }^{21}$ The very longest maturities respond surprisingly strongly to policy innovations. On non-policy days and endogenous policy days, above $40 \%$ of the movement in the 3 -month rate is transmitted to the 30-year rate, a phenomenon that is at odds with our model. Possibly this could be due to perceived changes in the Fed's inflation target: if the Fed is believed to adjust its target for inflation when the economy is hit by shocks, then this adjustment should be transmitted one-forone to long interest rates. This policy strategy, named the 'opportunistic approach,' has recently been discussed by, e.g., Orphanides and Wilcox (1996) and could possibly be incorporated into a model such as ours, but such work is beyond the scope of this paper.
} 
respond significantly differently to exogenous policy innovations as compared to endogenous policy, but the estimated response to policy moves is always positive.

To analyze the response of long rates on policy days in more detail, Table 3 presents the results for the 10- and 30-year rates from estimating four different regressions. We first estimate the average response for all 30 observations, with and without dummies for the term premium shifts. We then separate the endogenous and exogenous events, again both with and without term premium dummies.

When separating the groups, the explained variance in the interest rate response increases, especially when we do not control for the term premium shifts. In these regressions, the estimated slope coefficients for the exogenous events are negative. This negative coefficient, and most of the increase in explanatory power, disappears when controlling for the events of May and August 1994, but the classification still increases adjusted $R^{2}$ from 0.61 to 0.63 for the 10-year rate and from 0.55 to 0.60 for the 30-year rate. Thus, by classifying the Fed's policy moves, and controlling for two exceptional events, we explain about $60 \%$ of the variance in the longest interest rates in response to monetary policy actions. ${ }^{22}$

Although we can significantly separate the response of long rates to endogenous and exogenous events, the response of long rates to exogenous events is still positive. This result appears to contradict the first part of Hypothesis 1. However, as we shall now show, this result may well be due to the noise contained in daily data. On most days there will be some new information about the economy, creating a positive relationship between short and long interest rates, according to the results for nonpolicy days. Therefore the estimated slope coefficients for the exogenous events are biased upwards. We attempt to adjust this bias by calculating the implied slope coefficients for the true exogenous component from the hypothetical regression

$$
\Delta i_{t}^{n}=\alpha_{n}+\beta_{n}^{\mathrm{Ex} *} \Delta i_{t}^{\mathrm{Ex}}+\beta_{n}^{\mathrm{NP} *} \Delta i_{t}^{\mathrm{NP} *}+\varepsilon_{t}^{n}
$$

on the 9 exogenous observations which remain after we have excluded the events of May and August 1994. Here, $\Delta i_{t}^{\mathrm{Ex}}$ is the part of the policy innovation which is truly exogenous, due to a perceived change in the Fed's preferences, and $\Delta i_{t}^{\mathrm{NP}}$ is the 'non-policy event,' due to new information released on the policy day. Assuming that these non-policy events on exogenous policy days behave as on any non-policy day and are independent of the true exogenous component, we can calculate the

\footnotetext{
${ }^{22}$ Note that both estimated slope coefficients and standard errors differ between Tables 2 and 3. This is due to the constant term, which differs substantially between the two regressions, although it is always very small.
} 
Table 3: Response of long-term interest rates (10 and 30 years) on policy days

\begin{tabular}{|c|c|c|c|c|c|c|c|c|}
\hline & \multicolumn{2}{|c|}{$\overline{(i)}$} & \multicolumn{2}{|c|}{ (ii) } & \multicolumn{2}{|c|}{$($ (iii) } & \multicolumn{2}{|c|}{$(i v)$} \\
\hline & 10 years & 30 years & 10 years & 30 years & 10 years & 30 years & 10 years & 30 years \\
\hline$\alpha_{n}$ & $\begin{array}{c}-0.014 \\
(0.017)\end{array}$ & $\begin{array}{c}-0.015 \\
(0.015)\end{array}$ & $\begin{array}{c}0.008 \\
(0.012)\end{array}$ & $\begin{array}{c}0.005 \\
(0.010)\end{array}$ & $\begin{array}{c}-0.009 \\
(0.013)\end{array}$ & $\begin{array}{c}-0.010 \\
(0.011)\end{array}$ & $\begin{array}{c}0.007 \\
(0.011)\end{array}$ & $\begin{array}{c}0.004 \\
(0.009)\end{array}$ \\
\hline$\beta_{n}$ & $\begin{array}{c}0.317^{*} \\
(0.152)\end{array}$ & $\begin{array}{c}0.181 \\
(0.133)\end{array}$ & $\begin{array}{c}0.528^{* *} \\
(0.097)\end{array}$ & $\begin{array}{c}0.369^{* *} \\
(0.083)\end{array}$ & & & & \\
\hline$\beta_{n}^{\text {End }}$ & & & & & $\begin{array}{c}0.521^{* *} \\
(0.109)\end{array}$ & $\begin{array}{c}0.382^{* *} \\
(0.089)\end{array}$ & $\begin{array}{c}0.584^{* *} \\
(0.096)\end{array}$ & $\begin{array}{c}0.435^{* *} \\
(0.079)\end{array}$ \\
\hline$\beta_{n}^{\mathrm{Ex}}$ & & & & & $\begin{array}{c}-0.228 \\
(0.198)\end{array}$ & $\begin{array}{r}-0.357^{*} \\
(0.169)\end{array}$ & $\begin{array}{c}0.234 \\
(0.160)\end{array}$ & $\begin{array}{c}0.023 \\
(0.156)\end{array}$ \\
\hline$\gamma_{n}^{9405}$ & & & $\begin{array}{c}-0.245^{* *} \\
(0.015)\end{array}$ & $\begin{array}{c}-0.213^{* *} \\
(0.013)\end{array}$ & & & $\begin{array}{c}-0.229^{* *} \\
(0.016)\end{array}$ & $\begin{array}{c}-0.195^{* *} \\
(0.014)\end{array}$ \\
\hline$\gamma_{n}^{9408}$ & & & $\begin{array}{c}-0.208^{* *} \\
(0.026)\end{array}$ & $\begin{array}{c}-0.187^{* *} \\
(0.022)\end{array}$ & & & $\begin{array}{c}-0.157^{* *} \\
(0.033)\end{array}$ & $\begin{array}{c}-0.128^{* *} \\
(0.031)\end{array}$ \\
\hline $\bar{R}^{2}$ & 0.146 & 0.047 & 0.613 & 0.553 & 0.330 & 0.305 & 0.634 & 0.605 \\
\hline$\beta_{n}^{\text {End }}=\beta_{n}^{\text {Ex }}$ & & & & & $13.315^{* *}$ & $17.788^{* *}$ & $4.640^{*}$ & $6.567^{*}$ \\
\hline$\beta_{n}^{\mathrm{Ex}}$ & & & & & & & $\begin{array}{c}-0.017 \\
(0.169)\end{array}$ & $\begin{array}{r}-0.270^{\circ} \\
(0.131)\end{array}$ \\
\hline$\beta_{n}^{\mathrm{NP}^{*}}$ & & & & & & & $\begin{array}{r}0.557^{*} \\
(0.219)\end{array}$ & $\begin{array}{c}0.426^{*} \\
(0.169)\end{array}$ \\
\hline$\beta_{n}^{\mathrm{Ex}}=\beta_{n}^{\mathrm{NP}^{*}}$ & & & & & & & $4.312^{\circ}$ & $10.597^{*}$ \\
\hline
\end{tabular}

OLS estimation of

(i) $\Delta i_{t}^{n}=\alpha_{n}+\beta_{n} \Delta i_{t}^{3 \mathrm{~m}}+v_{t}^{n}$

(ii) $\Delta i_{t}^{n}=\alpha_{n}+\beta_{n} \Delta i_{t}^{3 \mathrm{~m}}+\gamma_{n}^{9405} d_{t}^{9405}+\gamma_{n}^{9408} d_{t}^{9408}+v_{t}^{n}$

(iii) $\Delta i_{t}^{n}=\alpha_{n}+\left(\beta_{n}^{\mathrm{End}} d_{t}^{\mathrm{End}}+\beta_{n}^{\mathrm{Ex}} d_{t}^{\mathrm{Ex}}\right) \Delta i_{t}^{3 \mathrm{~m}}+v_{t}^{n}$

(iv) $\Delta i_{t}^{n}=\alpha_{n}+\left(\beta_{n}^{\mathrm{End}} d_{t}^{\mathrm{End}}+\beta_{n}^{\mathrm{Ex}} d_{t}^{\mathrm{Ex}}\right) \Delta i_{t}^{3 \mathrm{~m}}+\gamma_{n}^{9405} d_{t}^{9405}+\gamma_{n}^{9408} d_{t}^{9408}+v_{t}^{n}$

on 30 policy events from October 3,1988 , to May 30, 1997. Wald-test $\left(\chi^{2}\right)$ of $\beta_{n}^{\text {End }}=\beta_{n}^{\text {Ex }}$ with 1 degree of freedom. White (1980) standard errors in parentheses, ${ }^{* *} /{ }^{*} /{ }^{\circ}$ denote significance at the $1 \%-, 5 \%$, and $10 \%$-level, respectively. $\beta_{n}^{\mathrm{Ex} *}$ and $\beta_{n}^{\mathrm{NP}^{*}}$ are the estimated coefficients from the hypothetical regression (38) on 9 exogenous policy events. (Hypothetical standard errors in parentheses not adjusted for heteroskedasticity. See Appendix F for details.) 
implied slope coefficient from equation (38) as

$$
\begin{aligned}
\beta_{n}^{\mathrm{Ex} *} & =\frac{\operatorname{Cov}\left(\Delta i_{t}^{\mathrm{Ex} *}, \Delta i_{t}^{n}\right)}{\operatorname{Var}\left(\Delta i_{t}^{\mathrm{Ex}}\right)} \\
& =\frac{\operatorname{Cov}\left(\Delta i_{t}^{3 \mathrm{~m}}, \Delta i_{t}^{n}\right)-\operatorname{Cov}\left(\Delta i_{t}^{\mathrm{NP} *}, \Delta i_{t}^{n}\right)}{\operatorname{Var}\left(\Delta i_{t}^{3 \mathrm{~m}}\right)-\operatorname{Var}\left(\Delta i_{t}^{\mathrm{NP}^{*}}\right)}
\end{aligned}
$$

where $\operatorname{Var}\left(\Delta i_{t}^{\mathrm{NP}^{*}}\right)$ and $\operatorname{Cov}\left(\Delta i_{t}^{\mathrm{NP}}, \Delta i_{t}^{n}\right)$ are calculated from the large sample of nonpolicy days. The resulting coefficients and estimated standard errors (not adjusted for heteroskedasticity) for the 10- and 30-year rates are reported in the lower panel of Table 3, along with a test of the restriction $\beta_{n}^{\mathrm{Ex}^{*}}=\beta_{n}^{\mathrm{NP}^{*}}$ (see Appendix F for details). After distilling the truly exogenous component, both the 10-year and the 30 -year rates respond negatively to exogenous policy innovations, and the latter response is significantly different from zero at the $10 \%$-level.

\section{Final remarks}

As mentioned in the Introduction, there is some confusion in the literature as to what should be the 'normal' response of long interest rates to monetary policy. Some authors argue that long rates should increase as monetary policy is tightened, mainly via the expectations hypothesis of the term structure. Others support the hypothesis that a monetary tightening should increase short rates but decrease long rates, as inflation expectations fall. Our results suggest that these differing views are two sides of the same coin. When long rates are determined via the expectations hypothesis, they may rise or fall after a policy tightening, depending on market participants' interpretation of the reasons behind the policy move.

An objection to our methodology concerns our classification. Since the story we want to convey is commonly heard in financial markets, it is conceivable that traders and analysts have our mechanism in mind when explaining the reaction of financial markets to monetary policy. Then our classification could be a result of the behavior of interest rates, and our empirical results only confirm this correspondence. However, this objection appears to be based on the presumption that interest rates are determined by fundamentals which could be unobservable to traders. Given the vast amount of 'speculative' trade, which is bound to dominate reactions in the short run, we are inclined to think that daily changes in interest rates are essentially determined by traders' beliefs. If so, causality is not a problem (unless traders jointly conspire to fool the readers of the Wall Street Journal).

Finally, we would like to put our work in a broader perspective. Apart from the 
response of interest rates to monetary policy, we also believe that our model has some interesting implications for the empirical literature on the effects of monetary policy on output; see, for example, Bernanke and Blinder (1992), Christiano, Eichenbaum and Evans (1996), Gordon and Leeper (1994), or Sims (1992). For this literature to be of much value, monetary policy should not be entirely endogenous; if the observed monetary policy actions are driven exclusively by developments in the economy, we cannot infer from these regressions what would have been the effect of a different monetary policy. Conventionally, modelers have derived the exogenous component of monetary policy from the econometric model itself. This approach has recently been challenged by Rudebusch (1998), who compares these VAR shocks to monetary policy shocks obtained from data on federal funds futures contracts. Since the two series of estimated shocks are quite dissimilar, Rudebusch concludes that "it would be surprising if VARs could provide even approximately correct answers to structural questions about the monetary transmission mechanism" (page 19). In a commentary, Sims (1998) points out that even if forecasts from the futures market have smaller errors than forecasts from a VAR, the estimated response to the VAR shocks may still be a good measure of the effects of monetary policy, something which is supported by the results of Brunner (1996) and Bagliano and Favero (1998).

We distinguish endogenous and exogenous changes in interest rates directly, by recording how bond traders interpret each movement in the federal funds rate target. In our view, this procedure delivers rather more credible estimates of exogenous policy shifts, which cannot be directly identified either by statistical methods or from futures data. It is conceivable that our data could be of use in settling the debate on the effects of exogenous policy shocks on the real economy. This issue, and many others, are left for future research. 


\section{A Determining $k\left(\lambda_{t}\right)$}

We want to determine $k_{t}=k\left(\lambda_{t}\right)$ in (12), which means determining $\pi_{t+2 \mid t+1}\left(\pi_{t+1 \mid t}\right)$. Substitute for $\pi_{t+2 \mid t}$ in (13), and solve for $y_{t+1 \mid t}$ :

$$
\begin{aligned}
y_{t+1 \mid t} & =-\frac{\alpha \delta k_{t}}{\lambda_{t}} \pi_{t+2 \mid t} \\
& =-\frac{\alpha \delta k_{t}}{\lambda_{t}}\left(\pi_{t+1 \mid t}+\alpha y_{t+1 \mid t}\right) \\
& =-\frac{\alpha \delta k_{t}}{\lambda_{t}+\alpha^{2} \delta k_{t}} \pi_{t+1 \mid t} .
\end{aligned}
$$

Then

$$
\begin{aligned}
\pi_{t+2 \mid t} & =\pi_{t+1 \mid t}+\alpha y_{t+1 \mid t} \\
& =\frac{\lambda_{t}}{\lambda_{t}+\alpha^{2} \delta k_{t}} \pi_{t+1 \mid t} .
\end{aligned}
$$

Use (12), apply the envelope theorem on the Bellman equation (7), use the law of iterated expectations, and substitute for $\pi_{t+2 \mid t}$ from (41) to get

$$
\begin{aligned}
V_{\pi}\left(\pi_{t+1 \mid t} ; \lambda_{t}\right) & =k_{t} \pi_{t+1 \mid t} \\
& =\pi_{t+1 \mid t}+\delta k_{t} \pi_{t+2 \mid t} \\
& =\left(1+\frac{\delta \lambda_{t} k_{t}}{\lambda_{t}+\alpha^{2} \delta k_{t}}\right) \pi_{t+1 \mid t}
\end{aligned}
$$

Thus,

$$
\begin{aligned}
& k_{t}=1+\frac{\delta \lambda_{t} k_{t}}{\lambda_{t}+\alpha^{2} \delta k_{t}}, \\
& k_{t}^{2}+\left(\frac{\lambda_{t}(1-\delta)}{\alpha^{2} \delta}-1\right) k_{t}-\frac{\lambda_{t}}{\alpha^{2} \delta}=0
\end{aligned}
$$

gives

$$
k_{t}=\frac{1}{2}\left[1-\frac{\lambda_{t}(1-\delta)}{\alpha^{2} \delta} \pm \sqrt{\left(1-\frac{\lambda_{t}(1-\delta)}{\alpha^{2} \delta}\right)^{2}+\frac{4 \lambda_{t}}{\alpha^{2} \delta}}\right]
$$

and the unique positive solution for $k_{t}$ is given by

$$
k_{t}=\frac{1}{2}\left[1-\frac{\lambda_{t}(1-\delta)}{\alpha^{2} \delta}+\sqrt{\left(1+\frac{\lambda_{t}(1-\delta)}{\alpha^{2} \delta}\right)^{2}+\frac{4 \lambda_{t}}{\alpha^{2}}}\right]
$$

following Svensson (1997b, p. 1141f). 


\section{B Evaluating $d A_{t} / d \lambda_{t}$}

Following Svensson (1997b, p. 1143), to evaluate the derivative

$$
\frac{d A_{t}}{d \lambda_{t}}=\frac{d}{d \lambda_{t}} \frac{\alpha \delta k_{t}}{\gamma\left(\lambda_{t}+\alpha^{2} \delta k_{t}\right)}
$$

consider the ratio

$$
\frac{k_{t}}{\lambda_{t}}=\frac{1}{2}\left[\frac{1}{\lambda_{t}}-\frac{(1-\delta)}{\alpha^{2} \delta}+\sqrt{\left(\frac{1}{\lambda_{t}}+\frac{(1-\delta)}{\alpha^{2} \delta}\right)^{2}+\frac{4}{\alpha^{2} \lambda_{t}}}\right],
$$

using (14). This expression is clearly decreasing in $\lambda_{t}$, so the inverse of $A_{t}$,

$$
\frac{1}{A_{t}}=\frac{\gamma\left(\lambda_{t}+\alpha^{2} \delta k_{t}\right)}{\alpha \delta k_{t}}=\frac{\gamma \lambda_{t}}{\alpha \delta k_{t}}+\alpha \gamma
$$

is increasing in $\lambda_{t}$. Consequently $A_{t}$ will be a decreasing function of $\lambda_{t}$. Also, since $B_{t}=\beta / \gamma+\alpha A_{t}, B_{t}$ is also decreasing in $\lambda_{t}$.

\section{Proofs}

\section{C.1 Proof of Proposition 1}

(i) $d i_{t}^{n} / d \varepsilon_{t}$ and $d i_{t}^{n} / d \eta_{t}>0$. For a supply shock, the expression in curly brackets in equation (31) is

$$
\begin{aligned}
& 1+A_{t}+\left[1+A_{t}\left(1-\gamma B_{t}\right)\right] X_{t}^{n} \\
& =1+A_{t}+X_{t}^{n}+\left(1-\beta-\alpha \gamma A_{t}\right) A_{t} X_{t}^{n} .
\end{aligned}
$$

Note that

$$
0<\alpha \gamma A_{t}=\frac{\alpha^{2} \delta k_{t}}{\lambda_{t}+\alpha^{2} \delta k_{t}} \leq 1
$$

which implies that

$$
0<\alpha \gamma A_{t} X_{t}^{n}=1-\left(1-\alpha \gamma A_{t}\right)^{n-1} \leq 1
$$

for all $n$. Consequently,

$$
\alpha \gamma A_{t}^{2} X_{t}^{n} \leq A_{t},
$$


which, since $\beta<1$, implies that the right-hand side of equation (50) and thus the derivative (31) are positive. Similarly, for a demand shock in (32), the expression in curly brackets

$$
\begin{aligned}
& B_{t}+\alpha\left[1+A_{t}\left(1-\gamma B_{t}\right)\right] X_{t}^{n} \\
& =\frac{\beta}{\gamma}+\alpha\left[A_{t}+X_{t}^{n}+\left(1-\beta-\alpha \gamma A_{t}\right) A_{t} X_{t}^{n}\right],
\end{aligned}
$$

is, by the same argument, also positive.

(ii) $d i_{t}^{n} / d \varepsilon_{t}$ and $d i_{t}^{n} / d \eta_{t}$ fall with maturity $n$. From equation (27), note that

$$
\frac{d i_{t+s \mid t}}{d \varepsilon_{t}}=\left(1-\alpha \gamma A_{t}\right) \frac{d i_{t+s-1 \mid t}}{d \varepsilon_{t}}
$$

and

$$
\frac{d i_{t+s \mid t}}{d \eta_{t}}=\left(1-\alpha \gamma A_{t}\right) \frac{d i_{t+s-1 \mid t}}{d \eta_{t}}
$$

Since $0<\alpha \gamma A_{t} \leq 1$, the response of expected future short rates to a current shock is non-increasing over time (in absolute terms). Since long rates are an average of expected short rates, and every new term will be smaller than the average, the entire average will decrease with maturity $n$.

\section{C.2 Proof of Proposition 2}

Recall that the long rate is given by

$$
i_{t}^{n}=\frac{1}{n}\left\{\left(1+A_{t}\right) \pi_{t}+B_{t} y_{t}+\left[1+A_{t}\left(1-\gamma B_{t}\right)\right] X_{t}^{n}\left[\pi_{t}+\alpha y_{t}\right]\right\}+\xi_{t}^{n},
$$

where

$$
X_{t}^{n}=\frac{1-\left(1-\alpha \gamma A_{t}\right)^{n-1}}{\alpha \gamma A_{t}}
$$

and $\xi_{t}^{n}$ is a term premium.

That the short end of the yield curve responds less to a given shock as $\lambda_{t}$ increases follows from the optimal interest rate rule

$$
i_{t}=\left(1+A_{t}\right) \pi_{t}+B_{t} y_{t}
$$

where $A_{t}$ and $B_{t}$ are decreasing in $\lambda_{t}$ (see Appendix B above). 
Showing that the long end responds more to a given shock with a higher $\lambda_{t}$ is more complicated. After a supply shock, the interest rate of maturity $n$ reacts according to

$$
\frac{d i_{t}^{n}}{d \varepsilon_{t}}=\frac{1}{n}\left\{1+A_{t}+\left[1+A_{t}\left(1-\gamma B_{t}\right)\right] X_{t}^{n}\right\} .
$$

As the central bank preference parameter $\lambda_{t}$ changes, this reaction changes by

$$
\begin{aligned}
& \frac{d}{d \lambda_{t}}\left[\frac{d i_{t}^{n}}{d \varepsilon_{t}}\right]=\frac{d}{d A_{t}} \frac{1}{n}\left\{1+A_{t}+X_{t}^{n}+\left[1-\alpha \gamma A_{t}-\beta\right] A_{t} X_{t}^{n}\right\} \frac{d A_{t}}{d \lambda_{t}} \\
& =\frac{1}{n}\left\{1+\frac{d X_{t}^{n}}{d A_{t}}-\alpha \gamma A_{t} X_{t}^{n}+\left[1-\alpha \gamma A_{t}-\beta\right] \frac{d\left(A_{t} X_{t}^{n}\right)}{d A_{t}}\right\} \frac{d A_{t}}{d \lambda_{t}} .
\end{aligned}
$$

Define $\rho_{t}=1-\alpha \gamma A_{t}$, implying that

$$
\begin{aligned}
& X_{t}=\frac{1-\rho_{t}^{n-1}}{1-\rho_{t}}, \\
& A_{t} X_{t}^{n}=\frac{1-\rho_{t}^{n-1}}{\alpha \gamma}, \\
& \alpha \gamma A_{t} X_{t}^{n}=1-\rho_{t}^{n-1},
\end{aligned}
$$

and

$$
\begin{aligned}
\frac{d X_{t}}{d A_{t}} & =\frac{d X_{t}}{d \rho_{t}} \frac{d \rho_{t}}{d A_{t}} \\
& =-\alpha \gamma \frac{-(n-1)\left(1-\rho_{t}\right) \rho_{t}^{n-2}+\left(1-\rho_{t}^{n-1}\right)}{\left(1-\rho_{t}\right)^{2}} \\
& =\frac{\rho_{t}^{n-2}\left[(n-1)\left(1-\rho_{t}\right)+\rho_{t}\right]-1}{\left(1-\rho_{t}\right) A_{t}} .
\end{aligned}
$$

Then

$$
\begin{aligned}
& \frac{d}{d \lambda_{t}}\left[\frac{d i_{t}^{n}}{d \varepsilon_{t}}\right]=\frac{1}{n}\left\{1+\frac{d X_{t}^{n}}{d A_{t}}-\alpha \gamma A_{t} X_{t}^{n}+\left(\rho_{t}-\beta\right) \frac{d\left(A_{t} X_{t}^{n}\right)}{d A_{t}}\right\} \frac{d A_{t}}{d \lambda_{t}} \\
& =\frac{1}{n}\left\{\rho_{t}^{n-1}+\frac{\rho_{t}^{n-2}\left[(n-1)\left(1-\rho_{t}\right)+\rho_{t}\right]-1}{\left(1-\rho_{t}\right) A_{t}}+\left(\rho_{t}-\beta\right)(n-1) \rho_{t}^{n-2}\right\} \frac{d A_{t}}{d \lambda_{t}} .
\end{aligned}
$$

Multiplying by $\left(1-\rho_{t}\right) A_{t} \geq 0$ and rearranging, the term in curly brackets is

$$
\rho_{t}^{n-2}(n-1)\left(1-\rho_{t}\right)\left[A_{t}\left(\rho_{t}-\beta\right)+1\right]+\rho_{t}^{n-1}\left[\left(1-\rho_{t}\right) A_{t}+1\right]-1 .
$$


As $n$ increases indefinitely, both $\rho_{t}^{n-1}$ and $(n-1) \rho_{t}^{n-2}$ tend to zero, making the term in (67) negative. Since $d A_{t} / d \lambda_{t}$ is negative, the entire derivative (66) is then positive for a sufficiently large $n$.

After a demand shock, the reaction of long rates is

$$
\begin{aligned}
\frac{d i_{t}^{n}}{d \eta_{t}} & =\frac{1}{n}\left\{B_{t}+\alpha\left[1+A_{t}\left(1-\gamma B_{t}\right)\right] X_{t}^{n}\right\} \\
& =\frac{1}{n}\left\{\frac{\beta}{\gamma}+\alpha\left[A_{t}+\left(1+A_{t}\left(1-\gamma B_{t}\right)\right) X_{t}^{n}\right]\right\} .
\end{aligned}
$$

Consequently

$$
\frac{d}{d \lambda_{t}}\left[\frac{d i_{t}^{n}}{d \eta_{t}}\right]=\alpha \frac{d}{d \lambda_{t}}\left[\frac{d i_{t}^{n}}{d \varepsilon_{t}}\right]
$$

so the reaction of long rates to a given demand shock is thus affected by changes in $\lambda_{t}$ in the same direction as the reaction to a supply shock.

\section{C.3 Proof of Proposition 4}

For a new shock, the proof follows directly from the proof of Proposition 2 in Appendix C.2. For an old shock being worked out by the central bank, note that (22) implies that the sensitivity of the central bank rate in period $t+s$ to a supply shock in period $t$ is

$$
\frac{d i_{t+s}}{d \varepsilon_{t}}=\left(1+A_{t+s}\right) \frac{d \pi_{t+s}}{d \varepsilon_{t}}+B_{t+s} \frac{d y_{t+s}}{d \varepsilon_{t}}
$$

Since $d \pi_{t+s} / d \varepsilon_{t}$ and $d y_{t+s} / d \varepsilon_{t}$ depend only on the initial $\lambda_{t}$, and so are not affected by the preference shift at $t+s$, and since $d B_{t} / d \lambda_{t}=\alpha d A_{t} / d \lambda_{t}$, the derivative of $d i_{t+s} / d \varepsilon_{t}$ with respect to $\lambda_{t+s}$ is, using (25) and (26),

$$
\begin{aligned}
\frac{d}{d \lambda_{t+s}}\left[\frac{d i_{t+s}}{d \varepsilon_{t}}\right] & =\left[\frac{d \pi_{t+s}}{d \varepsilon_{t}}+\alpha \frac{d y_{t+s}}{d \varepsilon_{t}}\right] \frac{d A_{t+s}}{d \lambda_{t+s}} \\
& =\left(1-\alpha \gamma A_{t}\right)^{s} \frac{d A_{t+s}}{d \lambda_{t+s}} \\
& =\left(1-\alpha \gamma A_{t}\right)^{s} \frac{d}{d \lambda_{t+s}}\left[\frac{d i_{t}}{d \varepsilon_{t}}\right]
\end{aligned}
$$

After $s$ periods, only a fraction $\left(1-\alpha \gamma A_{t}\right)^{s}$ of the shock from time $t$ remains in the system. Thus, the qualitative effects of a preference shift in period $t+s$ are the same as a change in period $t$, and the same applies to all long rates. 


\section{Classification of Federal Reserve actions}

\section{Classification:}

End Endogenous; based on new economic information

Ex Exogenous; based on preference shifts

R Employment report released on same day

$\mathrm{U} \quad$ Action unnoticed

\begin{tabular}{|c|c|c|c|c|}
\hline Event & Date & $\operatorname{Adj}(\%)$ & Description of event & Class \\
\hline 1 & Oct 20,1988 & +0.125 & $\begin{array}{l}\text { "...the Federal Reserve provided a hint that it } \\
\text { isn't tightening credit." }\end{array}$ & $\mathrm{U}$ \\
\hline 2 & Nov $17,1988^{1}$ & +0.0625 & $\begin{array}{l}\text { "Investment managers worry that the dollar's } \\
\text { weakness soon will lead to even higher interest } \\
\text { rates." }\end{array}$ & $\mathrm{U}$ \\
\hline 3 & Nov 22, 1988 & +0.0625 & No mention of monetary policy. & $\mathrm{U}$ \\
\hline 4 & Dec 15, 1988 & +0.3125 & $\begin{array}{l}\text { "Several recent economic reports have indicated } \\
\text { robust economic growth that aroused inflation jit- } \\
\text { ters." }\end{array}$ & End \\
\hline 5 & Dec $29,1988^{1}$ & +0.0625 & $\begin{array}{l}\text { "...the federal funds rate rose again, largely re- } \\
\text { flecting what traders refer to as 'year-end window } \\
\text { dressing'." }\end{array}$ & $\mathrm{U}$ \\
\hline 6 & Jan 5, 1989 & +0.25 & $\begin{array}{l}\text { "...the Fed's aggressive moves might encourage } \\
\text { bond investors by convincing them of the cent- } \\
\text { ral bank's determination to keep inflation under } \\
\text { control." }\end{array}$ & Ex \\
\hline 7 & Feb $9,1989^{1}$ & +0.0625 & $\begin{array}{l}\text { "Some analysts predict the Fed... will raise rates } \\
\text { Friday or early next week." }\end{array}$ & $\mathrm{U}$ \\
\hline 8 & Feb 14,1989 & +0.25 & $\begin{array}{l}\text { "Fed officials are tightening their credit clamp } \\
\text { further in an effort to rein in on inflation." } B e- \\
\text { fore: "IIf, as we expect, the Fed gradually nudges } \\
\text { the federal funds rate towards } 91 / 2 \% \text {, market } \\
\text { participants may regain faith that containing in- } \\
\text { flation remains a top priority for the monetary } \\
\text { authorities.'" }\end{array}$ & Ex \\
\hline 9 & Feb $23,1989^{1}$ & +0.25 & $\begin{array}{l}\text { "The Federal Reserve, trying to calm inflation } \\
\text { worries, drove up short-term interest rates." }\end{array}$ & End \\
\hline 10 & Feb $24,1989^{2}$ & +0.1875 & $\begin{array}{l}\text { "The Fed's long-awaited discount-rate increase } \\
\text { is too small and too late to help calm inflation } \\
\text { fears..." }\end{array}$ & Ex \\
\hline 11 & May $4,1989^{1}$ & +0.0625 & No mention of monetary policy. & $\mathrm{U}$ \\
\hline 12 & Jun 6,1989 & -0.25 & $\begin{array}{l}\text { "The U.S. Federal Reserve apparently has eased } \\
\text { its grip on credit, reflecting the belief of many Fed } \\
\text { officials that the economy has slowed..." }\end{array}$ & End \\
\hline
\end{tabular}




\begin{tabular}{|c|c|c|c|c|}
\hline Event & Date & $\operatorname{Adj}(\%)$ & Description of event & Class \\
\hline 13 & Jul 7, 1989 & -0.25 & $\begin{array}{l}\text { "...for several weeks now, strong signs of eco- } \\
\text { nomic weakness have convinced Fed officials to } \\
\text { ease instead." }\end{array}$ & End \\
\hline 14 & Jul 27, 1989 & -0.25 & $\begin{array}{l}\text { "...it became clear that the Federal Reserve is } \\
\text { easing credit and that the economy is growing } \\
\text { weaker." }\end{array}$ & End \\
\hline 15 & Aug $10,1989^{1}$ & -0.0625 & No mention of monetary policy. & $\mathrm{U}$ \\
\hline 16 & Oct 18,1989 & -0.25 & No mention of monetary policy. & $\mathrm{U}$ \\
\hline 17 & Nov 6,1989 & -0.25 & No mention of monetary policy. & $\mathrm{U}$ \\
\hline 18 & Dec 20, 1989 & -0.25 & $\begin{array}{l}\text { "Coming right after an FOMC meeting, they } \\
\text { would not have entered the market unless they } \\
\text { wanted to send a clear signal that policy had } \\
\text { changed." }\end{array}$ & Ex \\
\hline 19 & Jul 13, 1990 & -0.25 & $\begin{array}{l}\text { "Several investment managers fear that the Fed } \\
\text { pulled the trigger too soon..." } \\
\text { "If you're looking to the Fed as a bulwark against } \\
\text { inflation, then this doesn't support that case.". }\end{array}$ & Ex \\
\hline 20 & Oct 29,1990 & -0.25 & $\begin{array}{l}\text { "... widely anticipated move..." } \\
\text { Before: "... further signs of U.S. economic weak- } \\
\text { ness..." }\end{array}$ & End \\
\hline 21 & Nov 14, 1990 & -0.25 & $\begin{array}{l}\text { "...few investors are willing to participate in the } \\
\text { market until they see clear signs that the Federal } \\
\text { Reserve has eased monetary policy." }\end{array}$ & $\mathrm{U}$ \\
\hline 22 & Dec 7, 1990 & -0.25 & $\begin{array}{l}\text { "... [the Fed's] move came shortly after the } \\
\text { U.S. Labor Department reported a surge in the } \\
\text { November U.S. employment and sharp declines } \\
\text { in jobs." }\end{array}$ & $\mathrm{R}$ \\
\hline 23 & Dec $19,1990^{2}$ & -0.25 & $\begin{array}{l}\text { "... some disappointment that the Federal Re- } \\
\text { serve didn't signal a larger cut in the rate." }\end{array}$ & Ex \\
\hline 24 & Jan $8,1991^{3}$ & -0.25 & $\begin{array}{l}\text { "After yesterday's easing move, the new level for } \\
\text { the rate is believed to be } 63 / 4 \% \text {." }\end{array}$ & End \\
\hline 25 & Feb $1,1991^{2}$ & -0.5 & $\begin{array}{l}\text { "Prices of U.S. government bonds soared Friday } \\
\text { in response to a surprisingly weak U.S. employ- } \\
\text { ment report and a cut in the discount rate by the } \\
\text { Federal Reserve." }\end{array}$ & $\mathrm{R}$ \\
\hline 26 & Mar 8, 1991 & -0.25 & $\begin{array}{l}\text { "...they ignored the Department of Labor's re- } \\
\text { port that the unemployment rate rose to } 6.5 \% \\
\text { from } 6.2 \% \ldots \text { " }\end{array}$ & $\mathrm{R}$ \\
\hline 27 & Apr $30,1991^{2}$ & -0.25 & $\begin{array}{l}\text { "...the central bank surprised the market by } \\
\text { pushing rates another notch lower." } \\
\text { "... the move] didn't follow any major economic } \\
\text { report..." } \\
\text { "...'smacks of some political pressure on the } \\
\text { Fed." }\end{array}$ & Ex \\
\hline 28 & Aug 6, 1991 & -0.25 & $\begin{array}{l}\text { "On any kind of economic basis, the Fed move } \\
\text { was entirely justified'..." }\end{array}$ & End \\
\hline
\end{tabular}




\begin{tabular}{|c|c|c|c|c|}
\hline Event & Date & $\operatorname{Adj}(\%)$ & Description of event & Class \\
\hline 29 & Sep $13,1991^{2}$ & -0.25 & $\begin{array}{l}\text { "The U.S. Federal Reserve's latest move to cut in- } \\
\text { terest rates reflects its uneasiness about the slow } \\
\text { growth of money supply and the disappointingly } \\
\text { torpid economic recovery." }\end{array}$ & End \\
\hline 30 & Oct $30,1991^{3}$ & -0.25 & $\begin{array}{l}\text { "... by late afternoon, the Fed had eased at least } \\
25 \text { basis points..." } \\
\text { Before: "Evidence the recovery is wilting and in- } \\
\text { flation is waning..." }\end{array}$ & End \\
\hline 31 & Nov $6,1991^{2}$ & -0.25 & $\begin{array}{l}\text { "...the Federal Reserve Bank's surprise an- } \\
\text { nouncement of a discount rate cut." }\end{array}$ & End \\
\hline 32 & Dec 6, 1991 & -0.25 & $\begin{array}{l}\text { "...news from the U.S. Labor Department that } \\
\text { non-farm payrolls shrank } 241.000 \text { in November." }\end{array}$ & $\mathrm{R}$ \\
\hline 33 & Dec $20,1991^{2}$ & -0.5 & $\begin{array}{l}\text { "A still-faltering economy and slower inflation is } \\
\text { likely to cause U.S. interest rates to fall even fur- } \\
\text { ther..." } \\
\text { "... following the Federal Reserve's surprisingly } \\
\text { aggressive move on Friday..." }\end{array}$ & End \\
\hline 34 & Apr 9, 1992 & -0.25 & $\begin{array}{l}\text { "...the Fed's decision to cut rates...came } \\
\text { primarily for concerns about recent contractions } \\
\text { in the U.S. money supply." }\end{array}$ & End \\
\hline 35 & Jul 2, $1992^{2}$ & -0.5 & $\begin{array}{l}\text { "... a stunningly weak employment report, which } \\
\text { unlocked the door for lower interest rates." }\end{array}$ & $\mathrm{R}$ \\
\hline 36 & Sep 4, 1992 & -0.25 & $\begin{array}{l}\text { “... in the wake of Friday's extraordinarily weak } \\
\text { employment report." }\end{array}$ & $\mathrm{R}$ \\
\hline 37 & Feb 4, 1994 & +0.25 & $\begin{array}{l}\text { "The tightening came about three hours after } \\
\text { a weaker-than-expected January employment re- } \\
\text { port." }\end{array}$ & $\mathrm{R}$ \\
\hline 38 & Mar 22, 1994 & +0.25 & $\begin{array}{l}\text { Before: "Some studies show that inflationary } \\
\text { pressures are building..." } \\
\text { "...traders and investors had been expecting } \\
\text { such a move for some time..." }\end{array}$ & End \\
\hline 39 & Apr 18, 1994 & +0.25 & $\begin{array}{l}\text { Before: "... fear that we are going to see an ac- } \\
\text { celeration of inflation." } \\
\text { "... disappointment that the Fed didn't raise in- } \\
\text { terest rates by a larger margin." }\end{array}$ & End \\
\hline 40 & May $17,1994^{2}$ & +0.5 & $\begin{array}{l}\text { "... analysts said the Fed has indicated it will sit } \\
\text { tight for a little while..." } \\
\text { "...the action cleared the air of uncertainty that } \\
\text { had been restraining investors for months." }\end{array}$ & Ex \\
\hline 41 & Aug 16, $1994^{2}$ & +0.5 & $\begin{array}{l}\text { " } \ldots \text {... clear signal that the Fed intends to fight } \\
\text { inflation pressures,"” } \\
\text { "... improvement in inflation psychology..." }\end{array}$ & Ex \\
\hline 42 & Nov $15,1994^{2}$ & +0.75 & $\begin{array}{l}\text { "... bigger-than-expected boost in interest rates } \\
\text { by the U.S. Federal Reserve." } \\
\text { "... market participants view the Fed as doing } \\
\text { well in its effort to contain inflation." }\end{array}$ & $\mathrm{Ex}$ \\
\hline
\end{tabular}




\begin{tabular}{|c|c|c|c|c|}
\hline Event & Date & $\operatorname{Adj}(\%)$ & Description of event & Class \\
\hline 43 & Feb $1,1995^{2}$ & +0.5 & $\begin{array}{l}\text { "...the US Federal Reserve raised short-term } \\
\text { rates and indicated that there are only tentative } \\
\text { signs the economy is slowing." }\end{array}$ & End \\
\hline 44 & Jul 6, 1995 & -0.25 & $\begin{array}{l}\text { “...the Fed's willingness to ease ahead of Friday's } \\
\text { data suggests that the central bank is looking for } \\
\text { a weak employment report." }\end{array}$ & End \\
\hline 45 & Dec 19, 1995 & -0.25 & $\begin{array}{l}\text { ".... inflation has been somewhat more favorable } \\
\text { than anticipated..." }\end{array}$ & End \\
\hline 46 & Jan $31,1996^{2}$ & -0.25 & $\begin{array}{l}\text { "This rate cut says the Fed is likely to be more } \\
\text { aggressive cutting rates than people thought'..." }\end{array}$ & Ex \\
\hline 47 & Mar 25, 1997 & +0.25 & "...'the risk of inflation is increasing'..." & End \\
\hline
\end{tabular}

${ }^{1}$ No actual policy decision, according to Roley and Sellon (1996).

${ }^{2}$ Also discount rate change.

${ }^{3}$ Target change noticed one day before official target change. 


\section{E Interest rate data}

\begin{tabular}{|c|c|c|c|c|c|c|c|c|c|c|c|}
\hline Date & Target & Change & $3 \mathrm{~m}$ & $6 \mathrm{~m}$ & $1 \mathrm{y}$ & $2 \mathrm{y}$ & $3 y$ & $5 y$ & $7 y$ & $10 \mathrm{y}$ & $30 \mathrm{y}$ \\
\hline 881020 & 8.25 & +0.1250 & +0.02 & -0.01 & -0.01 & +0.00 & +0.00 & -0.01 & -0.02 & -0.03 & -0.06 \\
\hline 881117 & 8.3125 & +0.0625 & -0.02 & -0.02 & -0.02 & +0.00 & +0.03 & +0.03 & +0.05 & +0.06 & +0.04 \\
\hline 881122 & 8.3750 & +0.0625 & +0.01 & +0.08 & +0.07 & +0.07 & +0.08 & +0.07 & +0.05 & +0.05 & +0.01 \\
\hline 881215 & 8.6875 & +0.3125 & +0.07 & -0.08 & +0.05 & +0.00 & +0.01 & +0.02 & +0.00 & +0.00 & +0.01 \\
\hline 881229 & 8.75 & +0.0625 & -0.13 & -0.11 & -0.03 & -0.05 & -0.03 & -0.03 & -0.05 & -0.03 & +0.00 \\
\hline 890105 & 9.00 & +0.25 & +0.02 & +0.09 & +0.07 & +0.07 & +0.08 & +0.08 & +0.06 & +0.05 & +0.02 \\
\hline 890209 & 9.0625 & +0.0625 & -0.05 & -0.01 & +0.00 & +0.07 & +0.08 & +0.15 & +0.19 & +0.18 & +0.17 \\
\hline 890214 & 9.3125 & +0.25 & +0.01 & +0.05 & +0.04 & +0.04 & +0.02 & +0.05 & +0.04 & +0.03 & +0.04 \\
\hline 890223 & 9.5625 & +0.25 & +0.08 & +0.08 & +0.12 & +0.12 & +0.11 & +0.04 & +0.09 & +0.07 & +0.05 \\
\hline 890224 & 9.75 & +0.1875 & +0.04 & +0.13 & +0.03 & +0.06 & +0.02 & +0.02 & +0.01 & +0.02 & +0.01 \\
\hline 890504 & 9.8125 & +0.0625 & +0.00 & +0.02 & -0.01 & +0.00 & +0.00 & -0.01 & +0.00 & +0.00 & +0.04 \\
\hline 890606 & 9.5625 & -0.25 & -0.10 & -0.12 & +0.02 & +0.01 & +0.01 & +0.02 & +0.00 & +0.00 & -0.03 \\
\hline 890707 & 9.3125 & -0.25 & -0.04 & -0.04 & -0.06 & -0.11 & -0.07 & -0.05 & -0.07 & -0.06 & -0.06 \\
\hline 890727 & 9.0625 & -0.25 & -0.12 & -0.08 & -0.12 & -0.10 & -0.13 & -0.12 & -0.09 & -0.10 & -0.08 \\
\hline 890810 & 9.00 & -0.0625 & -0.05 & -0.01 & -0.02 & +0.00 & -0.01 & +0.00 & +0.00 & -0.03 & -0.04 \\
\hline 891018 & 8.75 & -0.25 & +0.07 & +0.02 & -0.01 & +0.00 & +0.00 & +0.00 & +0.03 & +0.01 & +0.02 \\
\hline 891106 & 8.50 & -0.25 & +0.03 & +0.04 & +0.04 & +0.03 & +0.05 & +0.06 & +0.06 & +0.04 & +0.05 \\
\hline 891220 & 8.25 & -0.25 & -0.10 & -0.09 & -0.08 & -0.08 & -0.03 & -0.02 & -0.03 & -0.01 & -0.01 \\
\hline 900713 & 8.00 & -0.25 & -0.08 & -0.06 & -0.07 & -0.07 & -0.06 & -0.05 & -0.06 & -0.05 & -0.04 \\
\hline 901029 & 7.75 & -0.25 & +0.02 & +0.03 & +0.02 & +0.02 & +0.04 & +0.04 & +0.06 & +0.07 & +0.08 \\
\hline 901114 & 7.50 & -0.25 & +0.03 & -0.02 & +0.01 & -0.02 & +0.00 & +0.00 & -0.01 & -0.01 & -0.01 \\
\hline 901207 & 7.25 & -0.25 & -0.11 & -0.13 & -0.13 & -0.15 & -0.15 & -0.15 & -0.15 & -0.15 & -0.16 \\
\hline 901219 & 7.00 & -0.25 & -0.11 & -0.13 & -0.12 & -0.07 & -0.03 & -0.03 & -0.01 & +0.01 & +0.04 \\
\hline 910108 & 6.75 & -0.25 & -0.07 & -0.10 & -0.08 & -0.05 & -0.04 & -0.01 & +0.02 & +0.03 & +0.05 \\
\hline 910201 & 6.25 & -0.50 & -0.19 & -0.23 & -0.22 & -0.22 & -0.20 & -0.17 & -0.14 & -0.12 & -0.12 \\
\hline 910308 & 6.00 & -0.25 & -0.10 & -0.10 & -0.09 & -0.04 & +0.01 & +0.04 & +0.04 & +0.06 & +0.07 \\
\hline 910430 & 5.75 & -0.25 & -0.08 & -0.14 & -0.14 & -0.10 & -0.07 & -0.07 & -0.05 & -0.05 & -0.03 \\
\hline 910806 & 5.50 & -0.25 & -0.09 & -0.11 & -0.12 & -0.12 & -0.14 & -0.08 & -0.07 & -0.07 & -0.06 \\
\hline 910913 & 5.25 & -0.25 & -0.06 & -0.05 & -0.03 & -0.02 & -0.02 & -0.02 & -0.04 & -0.01 & -0.01 \\
\hline 911030 & 5.00 & -0.25 & -0.05 & -0.06 & -0.05 & -0.05 & -0.02 & -0.03 & -0.01 & -0.03 & -0.01 \\
\hline 911106 & 4.75 & -0.25 & -0.13 & -0.11 & -0.08 & -0.07 & -0.07 & -0.07 & -0.05 & -0.05 & -0.01 \\
\hline 911206 & 4.50 & -0.25 & -0.07 & -0.09 & -0.07 & -0.03 & -0.02 & +0.01 & +0.03 & +0.05 & -0.08 \\
\hline 911220 & 4.00 & -0.50 & -0.30 & -0.29 & -0.26 & -0.25 & -0.20 & -0.17 & -0.14 & -0.14 & -0.09 \\
\hline 920409 & 3.75 & -0.25 & -0.21 & -0.22 & -0.23 & -0.24 & -0.22 & -0.17 & -0.12 & -0.09 & -0.09 \\
\hline 920702 & 3.25 & -0.50 & -0.31 & -0.29 & -0.32 & -0.27 & -0.23 & -0.25 & -0.20 & -0.17 & -0.13 \\
\hline 920904 & 3.00 & -0.25 & -0.22 & -0.23 & -0.23 & -0.20 & -0.21 & -0.20 & -0.17 & -0.14 & -0.08 \\
\hline 940204 & 3.25 & +0.25 & +0.10 & +0.11 & +0.17 & +0.14 & +0.15 & +0.15 & +0.14 & +0.13 & +0.06 \\
\hline 940322 & 3.50 & +0.25 & +0.00 & -0.06 & -0.07 & -0.06 & -0.11 & -0.11 & -0.12 & -0.11 & -0.09 \\
\hline 940418 & 3.75 & +0.25 & +0.11 & +0.14 & +0.16 & +0.19 & +0.20 & +0.20 & +0.20 & +0.17 & +0.12 \\
\hline 940517 & 4.25 & +0.50 & +0.05 & -0.05 & -0.11 & -0.15 & -0.17 & -0.19 & -0.23 & -0.21 & -0.19 \\
\hline 940816 & 4.75 & +0.50 & +0.17 & +0.02 & -0.01 & -0.05 & -0.06 & -0.10 & -0.12 & -0.11 & -0.12 \\
\hline 941115 & 5.50 & +0.75 & +0.10 & +0.09 & +0.05 & +0.04 & +0.04 & +0.03 & -0.02 & -0.02 & -0.04 \\
\hline 950201 & 6.00 & +0.50 & +0.07 & +0.08 & +0.11 & +0.07 & +0.05 & +0.02 & +0.07 & +0.06 & +0.04 \\
\hline 950706 & 5.75 & -0.25 & -0.14 & -0.17 & -0.17 & -0.22 & -0.20 & -0.20 & -0.15 & -0.14 & -0.10 \\
\hline 951219 & 5.50 & -0.25 & -0.11 & -0.09 & -0.09 & -0.07 & -0.06 & -0.08 & -0.06 & -0.04 & -0.06 \\
\hline 960131 & 5.25 & -0.25 & -0.08 & -0.07 & -0.07 & -0.09 & -0.07 & -0.05 & -0.05 & -0.03 & -0.01 \\
\hline 970325 & 5.50 & +0.25 & +0.04 & +0.02 & +0.03 & +0.04 & +0.03 & +0.05 & +0.03 & +0.03 & +0.01 \\
\hline
\end{tabular}

New level and adjustment of the federal funds rate target, one-day changes in market interest rates, and classification of 47 policy events October 1988-May 1997. Sources: Funds rate target 1988-92, Rudebusch (1995); Funds rate target 1993-97, Federal Reserve Bank of New York; Market interest rates, Federal Reserve Bank of St. Louis. 


\section{F Calculating the imputed coefficients and standard errors}

\section{F.1 General case}

Before analyzing our special case, let us consider a more general problem. Suppose we would like to estimate the regression

$$
y_{t}=\alpha+\beta_{1} x_{1, t}+\beta_{2} x_{2, t}+\varepsilon_{t}
$$

where $x_{1}$ and $x_{2}$ are independent variables. Recall that the least-squares estimate of $\beta_{i}, i=1,2$ is given by

$$
b_{i}=\frac{\operatorname{Cov}\left(x_{i}, y\right)}{\operatorname{Var}\left(x_{i}\right)},
$$

and its variance is

$$
\operatorname{Var}\left(b_{i}\right)=\frac{\sigma^{2}}{(N-1) \operatorname{Var}\left(x_{i}\right)},
$$

where the residual variance $\sigma^{2}$ is estimated as

$$
\hat{\sigma}^{2}=\frac{\sum_{h} e_{h}^{2}}{N-k} .
$$

The parameter $N$ is the number of observations in regression (72), and $k$ is the number of explanatory variables (here $k=3$ ).

Suppose we cannot observe $x_{1}$ and $x_{2}$ directly, but only their sum $x=x_{1}+x_{2}$. Thus, equation (72) cannot be estimated. However, if we have estimates from other sources of $\operatorname{Var}\left(x_{1}\right)$ and $\operatorname{Cov}\left(x_{1}, y\right)$, then we can calculate $\operatorname{Var}\left(x_{2}\right)$ and $\operatorname{Cov}\left(x_{2}, y\right)$ as

$$
\operatorname{Var}\left(x_{2}\right)=\operatorname{Var}(x)-\operatorname{Var}\left(x_{1}\right)
$$

and

$$
\operatorname{Cov}\left(x_{2}, y\right)=\operatorname{Cov}(x, y)-\operatorname{Cov}\left(x_{1}, y\right)
$$

since $x_{1}$ and $x_{2}$ are independent, and $\operatorname{Var}(x)$ and $\operatorname{Cov}(x, y)$ are known. Consequently, we can calculate the least-squares estimates of the slope coefficients for the hypothetical regression (72) from equation (73).

As for the variance of the slope coefficients, we need an expression for the hypothetical residual sum of squares. This sum can be computed $\operatorname{as}^{23}$

$$
\sum_{h} e_{h}^{2}=(N-1)\left[\operatorname{Var}(y)-b_{1} \operatorname{Cov}\left(x_{1}, y\right)-b_{2} \operatorname{Cov}\left(x_{2}, y\right)\right] .
$$

\footnotetext{
${ }^{23}$ Note that

$$
\sum_{h} e_{h}^{2}=\sum_{h} e_{h}\left[y_{h}-a-b_{1} x_{1 h}-b_{2} x_{2 h}\right]
$$
}


Table 4: Original regression results

\begin{tabular}{llllllllc}
\hline \hline & 6 months & 1 year & 2 years & 3 years & 5 years & 7 years & 10 years & 30 years \\
\hline$\beta_{n}$ & $1.283^{* *}$ & $0.953^{* *}$ & $0.861^{* *}$ & $0.577^{* *}$ & $0.527^{*}$ & 0.302 & 0.198 & -0.009 \\
& $(0.205)$ & $(0.180)$ & $(0.164)$ & $(0.160)$ & $(0.168)$ & $(0.178)$ & $(0.163)$ & $(0.159)$ \\
$\sum_{h}\left(e_{h}^{n}\right)^{2}$ & 0.01321 & 0.01019 & 0.00843 & 0.00801 & 0.00881 & 0.00989 & 0.00827 & 0.00795 \\
$\hat{\sigma}^{2}$ & 0.00189 & 0.00146 & 0.00120 & 0.00114 & 0.00126 & 0.00141 & 0.00118 & 0.00114 \\
$R^{2}$ & 0.848 & 0.799 & 0.797 & 0.650 & 0.585 & 0.291 & 0.175 & 0.001 \\
$\bar{R}^{2}$ & 0.826 & 0.771 & 0.768 & 0.600 & 0.526 & 0.190 & 0.057 & -0.142 \\
\hline
\end{tabular}

OLS estimation of equation (83) on 9 exogenous policy days. Constant terms not reported, standard errors in parentheses. ${ }^{* *} /{ }^{*}$ denote significance at the $1 \%-/ 5 \%$-level.

The estimated variance of $b_{i}$ is then calculated from equations (74) and (75). Finally, given the residual sum of squares, we can compute the measures of fit as

$$
R^{2}=1-\frac{\sum_{h} e_{h}^{2}}{\sum_{h} y_{h}^{2}}
$$

and

$$
\bar{R}^{2}=1-\frac{\sum_{h} e_{h}^{2} /(N-k)}{\sum_{h} y_{h}^{2} /(N-1)} .
$$

\section{F.2 Our case}

To translate these results into our setting, we would like to estimate

$$
\Delta i_{t}^{n}=\alpha_{n}+\beta_{n}^{\mathrm{Ex} *} \Delta i_{t}^{\mathrm{Ex} *}+\beta_{n}^{\mathrm{NP} *} \Delta i_{t}^{\mathrm{NP} *}+\varepsilon_{t}^{n},
$$

on our 9 exogenous policy events, where $\Delta i_{t}^{\mathrm{Ex} *}$ is the truly exogenous component of the policy innovation at $t$ and $\Delta i_{t}^{\mathrm{NP}}$ is the non-policy event of exogenous policy days. We cannot observe $\Delta i_{t}^{\mathrm{Ex}}$ and $\Delta i_{t}^{\mathrm{NP}^{*}}$ directly, however, but we can observe the total policy innovation

$$
\Delta i_{t}^{3 \mathrm{~m}}=\Delta i_{t}^{\mathrm{Ex}}+\Delta i_{t}^{\mathrm{NP}^{*}} .
$$

Thus we can estimate the regression

$$
\Delta i_{t}^{n}=\tilde{\alpha}_{n}+\beta_{n} \Delta i_{t}^{3 \mathrm{~m}}+\tilde{\varepsilon}_{t}^{n},
$$

and the results are reported in Table 4 .

$$
\begin{aligned}
& =\sum_{h}\left(y_{h}-\bar{y}\right)\left[\left(y_{h}-\bar{y}\right)-b_{1}\left(x_{1 h}-\bar{x}_{1}\right)-b_{2}\left(x_{2 h}-\bar{x}_{2}\right)\right] \\
& =\sum_{h}\left(y_{h}-\bar{y}\right)^{2}-\sum_{h} b_{1}\left(y_{h}-\bar{y}\right)\left(x_{1 h}-\bar{x}_{1}\right)-\sum_{h} b_{2}\left(y_{h}-\bar{y}\right)\left(x_{2 h}-\bar{x}_{2}\right),
\end{aligned}
$$

giving the expression in equation (78). See, for example, Gujarati (1988, section 7A.3). 
Assuming that the non-policy event of exogenous policy days behaves like on any non-policy day, we can approximate its variance and covariance with the dependent variable $\Delta i_{t}^{n}$ by those calculated over the 2,135 non-policy days. Also, the variance of the policy innovation $\Delta i_{t}^{3 \mathrm{~m}}$ and its covariance with the interest rate response $\Delta i_{t}^{n}$ on the 9 exogenous events are known.

Thus, assuming that the truly exogenous component and the non-policy event are independent, we can compute the variances of the truly exogenous component and its covariance with the dependent variable on the exogenous events as

$$
\operatorname{Var}\left(\Delta i_{t}^{\mathrm{Ex}}\right)=\operatorname{Var}\left(\Delta i_{t}^{3 \mathrm{~m}}\right)-\operatorname{Var}\left(\Delta i_{t}^{\mathrm{NP}}\right)
$$

and

$$
\operatorname{Cov}\left(\Delta i_{t}^{\mathrm{Ex} *}, \Delta i_{t}^{n}\right)=\operatorname{Cov}\left(\Delta i_{t}^{3 \mathrm{~m}}, \Delta i_{t}^{n}\right)-\operatorname{Cov}\left(\Delta i_{t}^{\mathrm{NP}}, \Delta i_{t}^{n}\right)
$$

The resulting variances and covariance for all maturities are reported in Table 5 .

Following the general discussion above, we are then able to calculate the leastsquares estimates from the hypothetical regression (81) as

$$
b_{n}^{j}=\frac{\operatorname{Cov}\left(\Delta i_{t}^{j}, \Delta i_{t}^{n}\right)}{\operatorname{Var}\left(\Delta i_{t}^{j}\right)}
$$

for $j=E x^{*}, N P^{*}$. To calculate the estimated variance of $b_{n}^{j}$, we first calculate the residual sum of squares as

$$
\begin{aligned}
\sum_{h}\left(e_{h}^{n}\right)^{2} & =(N-1) \\
\times & {\left[\operatorname{Var}\left(\Delta i_{t}^{n}\right)-b_{n}^{\mathrm{Ex} *} \operatorname{Cov}\left(\Delta i_{t}^{\mathrm{Ex} *}, \Delta i_{t}^{n}\right)-b_{n}^{\mathrm{NP} *} \operatorname{Cov}\left(\Delta i_{t}^{\mathrm{NP} *}, \Delta i_{t}^{n}\right)\right] }
\end{aligned}
$$

and the variance of $b_{n}^{j}$ is given by

$$
\operatorname{Var}\left(b_{n}^{j}\right)=\frac{\sum_{h}\left(e_{h}^{n}\right)^{2} /(N-k)}{(N-1) \operatorname{Var}\left(\Delta i_{t}^{j}\right)},
$$

and $R^{2}$ and $\bar{R}^{2}$ are calculated from equations (79) and (80). The results from the hypothetical regression (81) are presented in Table 6 . 
Table 5: Variances and covariances

\begin{tabular}{|c|c|c|c|c|c|c|c|c|}
\hline \multicolumn{9}{|c|}{ Policy innovation } \\
\hline $\operatorname{Var}\left(\Delta i_{t}^{3 \mathrm{~m}}\right)$ & 0.00559 & & & & & & & \\
\hline $\operatorname{Var}\left(\Delta i_{t}^{\mathrm{NP}^{*}}\right)$ & 0.00209 & & & & & & & \\
\hline $\operatorname{Var}\left(\Delta i_{t}^{t} \mathrm{Ex}^{*}\right)$ & 0.00349 & & & & & & & \\
\hline & 6 months & 1 year & 2 years & 3 years & 5 years & 7 years & 10 years & 30 years \\
\hline $\operatorname{Var}\left(\Delta i_{t}^{n}\right)$ & 0.01085 & 0.00634 & 0.00519 & 0.00286 & 0.00265 & 0.00174 & 0.00125 & 0.00099 \\
\hline $\operatorname{Cov}\left(\Delta i_{t}^{3 \mathrm{~m}}, \Delta i_{t}^{n}\right)$ & 0.00717 & 0.00532 & 0.00481 & 0.00322 & 0.00294 & 0.00168 & 0.00111 & -0.00005 \\
\hline $\operatorname{Cov}\left(\Delta i_{t}^{\mathrm{NP}}{ }^{*}, \Delta i_{t}^{n}\right)$ & 0.00169 & 0.00162 & 0.00174 & 0.00165 & 0.00151 & 0.00130 & 0.00117 & 0.00089 \\
\hline $\operatorname{Cov}\left(\Delta i_{t}^{\operatorname{Ex} *}, \Delta i_{t}^{n}\right)$ & 0.00548 & 0.00370 & 0.00307 & 0.00158 & 0.00143 & 0.00038 & -0.00006 & -0.00094 \\
\hline
\end{tabular}

$\operatorname{Var}\left(\Delta i_{t}^{3 \mathrm{~m}}\right), \operatorname{Var}\left(\Delta i_{t}^{n}\right)$, and $\operatorname{Cov}\left(\Delta i_{t}^{3 \mathrm{~m}}, \Delta i_{t}^{n}\right)$ are calculated over 9 exogenous policy days; $\operatorname{Var}\left(\Delta i_{t}^{\mathrm{NP} *}\right)$ and $\operatorname{Cov}\left(\Delta i_{t}^{\mathrm{NP}^{*}}, \Delta i_{t}^{n}\right)$ are calculated over 2,135 non-policy days; $\operatorname{Var}\left(\Delta i_{t}^{\mathrm{Ex}}\right)$ and $\operatorname{Cov}\left(\Delta i_{t}^{\mathrm{Ex}}, \Delta i_{t}^{n}\right)$ are computed according to equations (84) and (85).

Table 6: Hypothetical regression results

\begin{tabular}{llllllllc}
\hline \hline & 6 months & 1 year & 2 years & 3 years & 5 years & 7 years & 10 years & 30 years \\
\hline$\beta_{n}^{\text {Ex* }}$ & $1.568^{* *}$ & $1.060^{* *}$ & $0.879^{* *}$ & $0.451^{\circ}$ & 0.410 & 0.110 & -0.017 & $-0.270^{\circ}$ \\
& $(0.207)$ & $(0.236)$ & $(0.224)$ & $(0.202)$ & $(0.215)$ & $(0.207)$ & $(0.169)$ & $(0.131)$ \\
$\beta_{n}^{\mathrm{NP}^{*}}$ & $0.808^{*}$ & $0.773^{*}$ & $0.832^{*}$ & $0.787^{*}$ & $0.722^{*}$ & $0.621^{\circ}$ & $0.557^{*}$ & $0.426^{*}$ \\
& $(0.267)$ & $(0.305)$ & $(0.289)$ & $(0.261)$ & $(0.278)$ & $(0.267)$ & $(0.219)$ & $(0.169)$ \\
$\sum_{h}\left(e_{h}^{n}\right)^{2}$ & 0.00716 & 0.00933 & 0.00840 & 0.00683 & 0.00779 & 0.00715 & 0.00481 & 0.00287 \\
$\hat{\sigma}^{2}$ & 0.00119 & 0.00155 & 0.00140 & 0.00114 & 0.00130 & 0.00119 & 0.00080 & 0.00048 \\
$\sum_{h}\left(\Delta i_{h}^{n}\right)^{2}$ & 0.08870 & 0.06010 & 0.04600 & 0.02400 & 0.02140 & 0.01530 & 0.01030 & 0.00800 \\
$R^{2}$ & 0.919 & 0.845 & 0.817 & 0.716 & 0.636 & 0.532 & 0.533 & 0.641 \\
$\bar{R}^{2}$ & 0.892 & 0.793 & 0.756 & 0.621 & 0.515 & 0.377 & 0.377 & 0.521 \\
$\beta_{n}^{\mathrm{Ex}}=\beta_{n}^{\mathrm{NP}}$ & $5.075^{\circ}$ & 0.554 & 0.016 & 1.039 & 0.786 & 2.296 & $4.312^{\circ}$ & $10.597^{*}$ \\
\hline
\end{tabular}

Hypothetical OLS estimation of equation (81) on 9 exogenous observations. Constant terms not reported, standard errors in parentheses. ${ }^{* *} /{ }^{*} /{ }^{\circ}$ denote significance at the $1 \%-/ 5 \%-/ 10 \%$-level. 


\section{References}

Bagliano, Fabio C. and Carlo A. Favero, "Measuring monetary policy with VAR models: An evaluation," European Economic Review 42 (6), June 1998, 1069 1112 .

Balduzzi, Pierluigi, Edwin J. Elton, and T. Clifton Green, "Economic news and the yield curve: Evidence from the U.S. treasury market," mimeo, Boston College, October 1997.

Battellino, Ric, John Broadbent, and Philip Lowe, "The implementation of monetary policy in Australia," in The implementation and tactics of monetary policy, BIS Conference Papers Vol. 3, March 1997.

Bernanke, Ben S. and Alan Blinder, "The federal funds rate and the channels of monetary transmission," American Economic Review 82 (4), September 1992, 901-921.

Bernanke, Ben S. and Mark Gertler, "Inside the black box: The credit channel of monetary policy transmission," Journal of Economic Perspectives 9 (4), Fall 1995, 27-48.

Blinder, Alan S., "Is there a core of practical macroeconomics that we should all believe?," American Economic Review 87 (2), May 1997, 240-243.

Brunner, Allan D., "Using measures of expectations to identify the effects of a monetary policy shock," International Finance Discussion Paper No. 537, Board of Governors of the Federal Reserve, January 1996.

Buttiglione, Luigi, Paolo Del Giovane, and Eugenio Gaiotti, "Implementation of monetary policy in Italy: The role of repo operations and official rates," in The implementation and tactics of monetary policy, Bank for International Settlements Conference Papers Vol. 3, March 1997.

Campbell, John Y., "Some lessons from the yield curve," Journal of Economic Perspectives 9 (3), Summer 1995, 129-152.

Christiano, Lawrence J., Martin Eichenbaum, and Charles Evans, "The effects of monetary policy shocks: Evidence from the flow of funds," Review of Economics and Statistics 78 (1), February 1996, 16-34. 
Cook, Timothy and Thomas Hahn, "The effect of changes in the federal funds rate target on market interest rates in the 1970s," Journal of Monetary Economics 24 (3), November 1989, 331-351.

Cook, Timothy and Steven Korn, "The reaction of interest rates to the employment report: The role of policy anticipation," Federal Reserve Bank of Richmond Economic Review 77 (5), September-October 1991, 3-12.

Gordon, David B. and Eric M. Leeper, "The dynamic impacts of monetary policy: An exercise in tentative identification," Journal of Political Economy 102 (6), December 1994, 1228-1247.

Gujarati, Damodar N., Basic econometrics, McGraw-Hill, New York, 1988.

Harvey, Campbell R. and Roger D. Huang, "The impact of the Federal Reserve Bank's open market operations," Working Paper No. 4663, National Bureau of Economic Research, February 1994.

Lindberg, Hans, Kerstin Mitlid, and Peter Sellin, "Monetary tactics with an inflation target: The Swedish case," in The implementation and tactics of monetary policy, Bank for International Settlements Conference Papers Vol. 3, March 1997.

Mankiw, N. Gregory and Jeffrey A. Miron, "The changing behavior of the term structure of interest rates," Quarterly Journal of Economics 101 (2), May 1986, 211-228.

McCallum, Bennett T., "Monetary policy and the term structure of interest rates," Working Paper No. 4938, National Bureau of Economic Research, November 1994.

Mehra, Yash, "Monetary policy and long-term interest rates," Federal Reserve Bank of Richmond Economic Quarterly 82 (3), Summer 1996, 27-49.

Mellin, Stefan, "Inflation target instability and interest rates," Research Paper No. 1997:4 WE, University of Stockholm, February 1997.

Orphanides, Athanasios and David W. Wilcox, "The opportunistic approach to disinflation," Finance and Economics Discussion Paper No. 96-24, Board of Governors of the Federal Reserve, May 1996. 
Roley, V. Vance and Gordon H. Sellon, Jr., "Monetary policy actions and long-term interest rates," Federal Reserve Bank of Kansas City Economic Review Fourth quarter 1995, 73-89.

, "The response of the term structure of interest rates to federal funds rate target changes," Research Working Paper No. 96-08, Federal Reserve Bank of Kansas City, November 1996.

Romer, Christina D. and David H. Romer, "Federal Reserve private information and the behavior of interest rates," Working Paper No. 5692, National Bureau of Economic Research, July 1996.

Rudebusch, Glenn D., "Federal Reserve interest rate targeting, rational expectations, and the term structure," Journal of Monetary Economics 35 (2), April $1995,245-274$.

_ - "Do measures of monetary policy in a VAR make sense?," International Economic Review 39 (4), November 1998, 907-931.

Rudebusch, Glenn D. and Lars E. O. Svensson, "Policy rules for inflation targeting," Working Paper No. 6512, National Bureau of Economic Research, April 1998.

Sims, Christopher A., "Interpreting the macroeconomic time series facts: The effects of monetary policy," European Economic Review 36 (5), June 1992, 975-1000.

_ - "Comment on Glenn Rudebusch's 'Do measures of monetary policy in a VAR make sense?'," International Economic Review 39 (4), November 1998, 933-941.

Skinner, Tom and Jerónimo Zettelmeyer, "Long rates and monetary policy: Is Europe different?," in Zettelmeyer, J., Essays on monetary policy, Ph.D. dissertation, Massachusetts Institute of Technology, February 1995.

Söderström, Ulf, "Predicting monetary policy using federal funds futures prices," Working Paper in Economics and Finance No. 307, Stockholm School of Economics, March 1999(a).

"Monetary policy with uncertain parameters," Working Paper in Economics and Finance No. 308, Stockholm School of Economics, March 1999(b).

Svensson, Lars E. O., "Inflation targeting: Some extensions," Working Paper No. 5962, National Bureau of Economic Research, March 1997(a). 
— - "Inflation forecast targeting: Implementing and monitoring inflation targets," European Economic Review 41 (6), June 1997(b), 1111-1146.

Taylor, John B., "Discretion versus policy rules in practice," Carnegie-Rochester Conference Series on Public Policy 39, December 1993, 195-214.

White, Halbert, "A heteroskedasticity-consistent covariance matrix estimator and a direct test for heteroskedasticity," Econometrica 48 (4), May 1980, 817-838. 